\title{
Discriminant Analysis for the Eigenvalues of Variance Covariance Matrix of FFT Scaling of DNA Sequences: An Empirical Study of Some Organisms
}

\author{
Salah Hamza Abid ${ }^{1,}$, Jinan Hamza Farhood ${ }^{2}$ \\ ${ }^{1}$ Mathematics Department, Education College, Al-Mustansiriya University, Baghdad, Iraq \\ ${ }^{2}$ Mathematics Department, Education College, Babylon University, Babil, Iraq \\ Email address: \\ abidsalah@uomustansiriyah.edu.iq (S. H. Abid) \\ ${ }^{*}$ Corresponding author
}

To cite this article:

Salah Hamza Abid, Jinan Hamza Farhood. Discriminant Analysis for the Eigenvalues of Variance Covariance Matrix of FFT Scaling of DNA Sequences: An Empirical Study of Some Organisms. International Journal of Intelligent Information Systems.

Vol. 8, No. 1, 2019, pp. 26-42. doi: 10.11648/j.ijiis.20190801.15

Received: January 19, 2019; Accepted: March 11, 2019; Published: March 27, 2019

\begin{abstract}
Many studies discussed different numerical representations of DNA sequences. One naive approach for exploring the nature of a DNA sequence is to assign numerical values (or scales) to the nucleotides and then proceed with standard time series methods. The analysis will depend actually on the particular assignment of numerical values.Discriminant analysis aims to examine the dependence of one qualitative (classification) variable from several quantitative variables according to number of variations of qualitative variable we can distinction. Actually, there is a discriminant analysis for two or more groups. The essential work of discriminant analysis is to get the optimal assigning rules that will minimize the likelihood of incorrect classification of elements. In this paper, we discussed the discriminant analysis of the first, second, third and fourth eigenvalues of variance covariance matrix of Fast Fourier Transform (FFT) for numerical values representation of DNA sequences of five organisms, Human, E. coli, Rat, Wheat and Grasshopper. The analysis is based on three methods (All Variables, Forward Selection and Backward Selection) of discrimination. Functions have been reached whereby discrimination is made among organisms under consideration. Empirical studies are conducted to show the value of our point of view and the applications based on. Therefore, we recommended that, other empirical studies should be done for other organisms and statistical methods by using the point of view adopted here. Also, aspects stated here must be used in an applied manner for DNA sequences discrimination.
\end{abstract}

Keywords: FFT Scaling, DNA, Classification, Discriminant Analysis (DA), All Variables, Forward Selection, Backward Selection, Wilks-Lambda, Eigenvalue

\section{Introduction}

Discriminant analysis is a multivariate statistical analysis method that serves to set up a model to predict group memberships. The model consists of discriminant functions that appear based on a linear combination of predictive variables that provide the best discrimination between groups. These functions are derived from a sample whose group memberships are known. Afterward, they could be applied to new individuals or units with measures related to the same variables and unknown group memberships. Thus, although discriminant analysis is not frequently used in behavioral sciences because its assumptions are not always easy to meet, it is a conceptually and mathematically powerful multivarite statistical method. Therefore, a description and illustration of the discriminant analysis method may help increase its use [1].

In different areas of applications the term "discriminant analysis" has come to imply distinct meanings, uses, roles, etc. In the fields of learning, psychology, guidance, and others, it has been used for prediction [2-4]; in the study of classroom instruction it has been used as avariable reduction technique [5]; and in various fields it has been used as an adjunct to MANOVA [6]. In this sense, discriminant analysis 
as a general research technique can be very useful in the investigation of various aspects of a multivariate research problem. Tatsuoka and Tiedeman [7] emphasized the multiphasic character of discriminant analysis in the early 1950s: (a) the establishment of significant group-differences, (b) the study and 'explanation' of these differences, and finally (c) the utilization of multivariate information from the samples studied in classifying a future individual known to belong to one of the groups represented. Essentially these same three problems related to discriminatory analysis.

Originally developed in 1936 by R. A. Fisher [8, 9], Discriminant Analysis is a classic method of classification that has stood the test of time. Discriminant analysis often produces models whose accuracy approaches (and occasionally exceeds) more complex modern methods. Discriminant analysis can be used only for classification (i.e., with a categorical target variable), not for regression. The target variable may have two or more categorical data.

Discriminant analysis is a powerful statistical pattern recognition method which has been applied to many DNA sequence motif finding problems. On other words, discriminant analysis is widely used in biological analyzes, including DNA analysis. Some of the relevant scientific literatures are as follows.

Solovyev and Salamov [10], introduced a complex of new programs for promoter, 3'-processing, splice sites, coding exons and gene structure identification in genomic DNA of several model species. The human gene structure prediction program FGENEH, exon prediction - FEXH and splice site prediction - HSPL have been modified for sequence analysis of Drosophila (FGENED, FEXD and DSPL), C. elegance (FGENEN, FEXN and NSPL), Yeast (FEXY and YSPL) and Plant (FGENEA, FEXA and ASPL) genomic sequences. They recomputed all frequency and discriminant function parameters for these organisms and adjusted organism specific minimal intron lengths. An accuracy of coding region prediction for these programs is similar with the observed accuracy of FEXH and FGENEH. They have developed FEXHB and FGENEHB programs combining pattern recognition features and information about similarity of predicted exons with known sequences in protein databases. These programs have approximately $10 \%$ higher average accuracy of coding region recognition. Two new programs for human promoter site prediction (TSSG and TSSW) have been developed which use Ghosh [11] and Wingender [12] data bases functional motifs, respectively. POLYAH program was designed for prediction of 3"processing regions in human genes and CDSB program was developed for bacterial gene prediction. They have developed a new approach to predict multiple genes based on double dynamic programming, that is very important for analysis of long genomic DNA fragments generated by genome sequencing projects.

Since the identification of functional motifs in a DNA sequence is fundamentally a statistical pattern recognition problem. Discriminant analysis is widely used for solving such problems. Zhang [13], described two basic parametric methods: LDA (linear discriminant analysis) and QDA (quadracic discriminant analysis). He demonstrated their usage in recognition of splice sites and exons in the human genome.

Dudoit et al. [14] compared the performance of difierent discrimination methods for the classification of tumors based on gene expression data. These methods included: nearest neighbor classifiers, linear discriminant analysis, and classifcation trees. They also considered recent machine learning approaches such as bagging and boosting. They investigated the use of prediction votes to assess the confidence of each prediction. The methods are applied to datasets from three recently published cancer gene expression studies.

Kwon et al. [15] finded the causal relationship between several tumors and the gene-expression data by sequentially using the stepwise discriminant analysis method (SDA) and Bayesian decision theory (BDT). Eighty-five samples containing four tumor classes are used in this study. The classes are neuroblastoma (NB), rhabdomyosarcoma (RMS), non-Hodgkin lymphoma (BL) and the Ewing family of tumor (EWS). SDA is used to select critical genes for accurate classification of 4 tumors from original 2308 genes. With the selected genes, Bayesian classifier is made, which minimizes the misclassification rate. As a result, the classification performance increased to $100 \%$ and 9 new genes that have relation with the development of the tumors is found additionally.

Liu et al. [16] analyzed various functional regions of the human genome based on sequence fea- tures, including word frequency, dinucleotide relative abundance, and base-base correlation. They analyzed the human chromosome 22 and classified the upstream, exon, intron, downstream, and intergenic regions by principal component analysis and discriminant analysis of these features. The results show that they could classify the functional regions of genome based on sequence feature and discriminant analysis.

Guo et al. [17] in the same year, presented a modified version of linear discriminant analysis, called "shrunken centroids regularized discriminant analysis" (SCRDA). The SCRDA method is specially designed for classification problems in high dimension low sample size situations, for example, microarray data. Through both simulated data and real life data, it is shown that this method performed very well in multivariate classification problems, often outperforms the PAM method and can be as competitive as the SVM classifiers. It is also suitable for feature elimination purpose and can be used as gene selection method.

Jombart et al. [18], proposed the discriminant analysis of principal components (DAPC), a multivariate method designed to identify and describe clusters of genetically related individuals. When group priors are lacking, DAPC uses sequential K-means and model selection to infer genetic clusters. They evaluated the performance of our method using simulated data, which were also analyzed using STRUCTURE as a benchmark. Additionally, they illustrated the method by analyzing microsatellite polymorphism in 
worldwide human populations and hemagglutinin gene sequence variation in seasonal influenza.

It is well known that outliers are present in virtually every data set in any application domain, and classical discriminant analysis methods (including linear discriminant analysis (LDA) and quadratic discriminant analysis (QDA)) do not work well if the data set has outliers. In order to overcome the difficulty, Jin and An [19] used the robust statistical method. They choosed four different coding characters as discriminant variables and an approving result is presented by the method of robust discriminant analysis.

Libbrecht et al. [20], provided an overview of machine learning applications for the analysis of genome sequencing data sets, including the annotation of sequence elements and epigenetic, proteomic or metabolomic data. They introduced considerations and recurrent challenges in the application of supervised, semi-supervised and unsupervised machine learning methods, as well as of generative and discriminative modelling approaches. They provided general guidelines to assist in the selection of these machine learning methods and their practical application for the analysis of genetic and genomic data sets.

Corvelo et al. [21], introduced taxMaps, a highly efficient, sensitive, and fully scalable taxonomic classification tool. Using a combination of simulated and real metagenomics data sets, they demonstrate that taxMaps is more sensitive and more precise than widely used taxonomic classifiers and is capable of delivering classification accuracy comparable to that of BLASTN, but at up to three orders of magnitude less computational cost.

\section{DNA Sequence}

In the process of developing the technology, many possible interesting adaptations became apparent: One of the most interesting directions was the use of the technology in the analysis of long DNA sequences. A benefit of the techniques was that it combined rigorous statistical analysis with modern computer power to quickly search for diagnostic patterns within long DNA sequences. Briefly, a DNA strand can be viewed as a long string of linked nucleotides. Each nucleotide is composed of a nitrogenous base, a five carbon sugar, and a phosphate group. There are four different bases that can be grouped by size, the pyrimidines, thymine $(\mathrm{T})$ and cytosine $(\mathrm{C})$, and the purines, adenine $(A)$ and guanine $(\mathrm{G})$. The nucleotides are linked together by a backbone of alternating sugar and phosphate groups with the $5^{\prime}$ carbon of one sugar linked to the $3^{\prime}$ carbon of the next, giving the string direction. DNA molecules occur naturally as a double helix composed of polynucleotide strands with the bases facing inward. The two strands are complementary, so it is sufficient to represent a DNA molecule by a sequence of bases on a single strand; refer to Figure 1. Thus, a strand of DNA can be represented as a sequence $\left\{X_{t} ; t=1,2, \ldots, n\right\}$ of letters, termed base pairs $(b p)$, from the finite alphabet $\{A, C, G, T\} .1$ The order of the nucleotides contains the genetic information specific to the organism. Expression of information stored in these molecules is a complex multistage process. One important task is to translate the information stored in the protein-coding sequences (CDS) of the DNA (Polovinkina et al. (2016) [22]).

A common problem in analyzing long DNA sequence data is in identifying CDS that are dispersed throughout the sequence and separated by regions of noncoding (which makes up most of the DNA). Another problem of interest that we will address here is that of matching two DNA sequences, say $X_{1 t}$ and $X_{2 t}$. The background behind the problem is discussed in detail in the study by Waterman and Vingron [23]. For example, every new DNA or protein sequence is compared with one or more sequence databases to find similar or homologous sequences that have already been studied, and there are numerous examples of important discoveries resulting from these database searches.

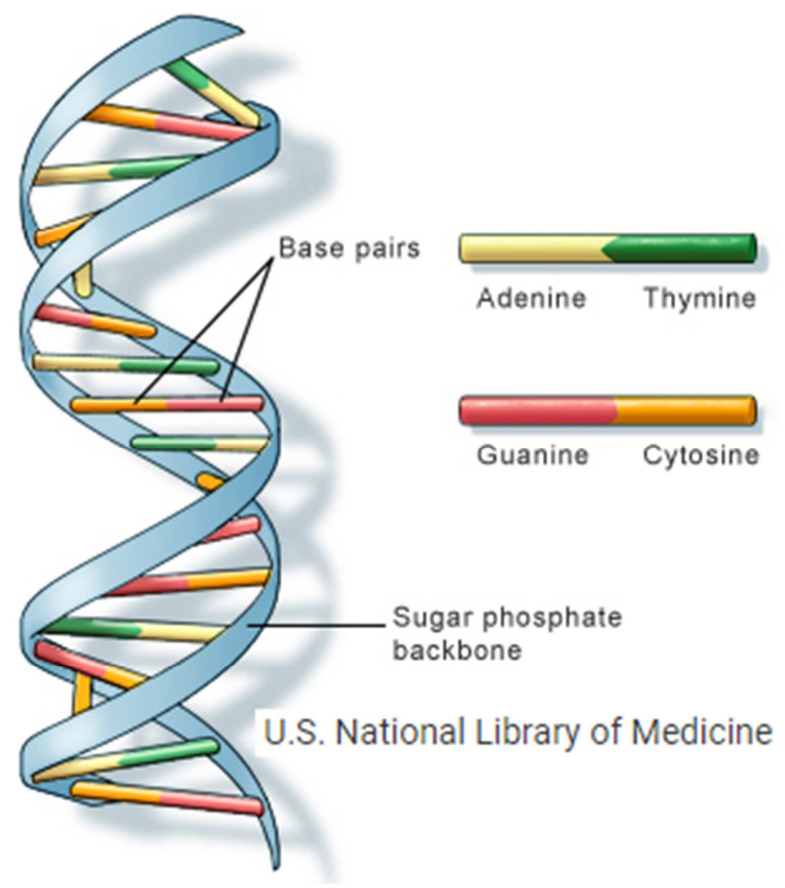

Figure 1. The general structure of DNA and its bases.

One naive approach for exploring the nature of a DNA sequence is to assign numerical values (or scales) to the nucleotides and then proceed with standard time series methods. It is clear, however, that the analysis will depend on the particular assignment of numerical values. Consider the artificial sequence ACGTACGTACGT... Then, setting $A=G$ $=0$ and $\mathrm{C}=\mathrm{T}=1$, yields the numerical sequence $010101010101 \ldots$, or one cycle every two base pairs (i.e., a frequency of oscillation of $\omega=1 / 2 \mathrm{Cycle} / \mathrm{bp}$, or a period of oscillation of length $1 / \omega=2 \mathrm{bp}=$ cycle). Another interesting scaling is $A=1, C=2, G=3$, and $T=4$, which results in the sequence $123412341234 \ldots$, or one cycle every four bp $(\omega=1 / 4)$. In this example, both scalings of the nucleotides are interesting and bring out different properties of the sequence. It is clear, then, that one does not want to focus on only one scaling. Instead, the focus should be on finding all possible scalings that bring our interesting features of the 
data. Rather than choose values arbitrarily, the spectral envelope approach selects scales that help emphasize any periodic feature that exists in a DNA sequence of virtually any length in a quick and automated fashion. In addition, the technique can determine whether a sequence is merely a random assignment of letters [22]).

Fourier analysis has been applied successfully in DNA analysis; McLachlan and Stewart [24] and Eisenberg et al. [25] studied the periodicity in proteins using Fourier analysis.

Stoffer et al. [26] proposed the spectral envelope as a general technique for analyzing categorical-valued time series in the frequency domain. The basic technique is similar to the methods established by Tavar'e and Giddings [27] and Viari et al. [28], however, there are some differences. The main difference is that the spectral envelope methodology is developed in a statistical setting to allow the investigator to distinguish between significant results and those results that can be attributed to chance.

The article authored by Marhon and Kremer [29], partitions the identification of protein-coding regions into four discrete steps. Based on this partitioning, digital signal processing DSP techniques can be easily described and compared based on their unique implementations of the processing steps. They compared the approaches, and discussed strengths and weaknesses of each in the context of different applications. Their work provides an accessible introduction and comparative review of DSP methods for the identification of protein-coding regions. Additionally, by breaking down the approaches into four steps, they suggested new combinations that may be worthy of future studies. A new methodology for the analysis of DNA/RNA and protein sequences is presented by Bajic [30]. It is based on a combined application of spectral analysis and artificial neural networks for extraction of common spectral characterization of a group of sequences that have the same or similar biological functions. The method does not rely on homology comparison and provides a novel insight into the inherent structural features of a functional group of biological sequences. The nature of the method allows possible applications to a number of relevant problems such as recognition of membership of a particular sequence to a specific functional group or localization of an unknown sequence of a specific functional group within a longer sequence. The results are of general nature and represent an attempt to introduce a new methodology to the field of biocomputing. Fourier transform infrared (FTIR) spectroscopy has been considered by Han et al. [31] as a powerful tool for analysing the characteristics of DNA sequence. This work investigated the key factors in FTIR spectroscopic analysis of DNA and explored the influence of FTIR acquisition parameters, including FTIR sampling techniques, pretreatment temperature, and sample concentration, on calf thymus DNA. The results showed that the FTIR sampling techniques had a significant influence on the spectral characteristics, spectral quality, and sampling efficiency. Ruiz et al. [32] proposed a novel approach for performing cluster analysis of DNA sequences that is based on the use of Genomic signal processing GSP methods and the K-means algorithm. We also propose a visualization method that facilitates the easy inspection and analysis of the results and possible hidden behaviors. Our results support the feasibility of employing the proposed method to find and easily visualize interesting features of sets of DNA data. A novel clustering method is proposed by Hoang et al. [33] to classify genes and genomes. For a given DNA sequence, a binary indicator sequence of each nucleotide is constructed, and Discrete Fourier Transform is applied on these four sequences to attain respective power spectra. Mathematical moments are built from these spectra, and multidimensional vectors of real numbers are constructed from these moments. Cluster analysis is then performed in order to determine the evolutionary relationship between DNA sequences. The novelty of this method is that sequences with different lengths can be compared easily via the use of power spectra and moments. Experimental results on various datasets show that the proposed method provides an efficient tool to classify genes and genomes. It not only gives comparable results but also is remarkably faster than other multiple sequence alignment and alignment-free methods. One challenge of GSP is how to minimize the error of detection of the protein coding region in a specified DNA sequence with a minimum processing time. Since the type of numerical representation of a DNA sequence extremely affects the prediction accuracy and precision, by this study Mabrouk [34] aimed to compare different DNA numerical representations by measuring the sensitivity, specificity, correlation coefficient (CC) and the processing time for the protein coding region detection. The proposed technique based on digital filters was used to read-out the period 3 components and to eliminate the unwanted noise from DNA sequence. This method applied to 20 human genes demonstrated that the maximum accuracy and minimum processing time are for the 2-bit binary representation method comparing to the other used representation methods. Results suggest that using 2-bit binary representation method significantly enhanced the accuracy of detection and efficiency of the prediction of coding regions using digital filters. Identification and analysis of hidden features of coding and non-coding regions of DNA sequence is a challenging problem in the area of genomics. The objective of the paper authored by Roy and Barman [35] is to estimate and compare spectral content of coding and non-coding segments of DNA sequence both by Parametric and Nonparametric methods. Consequently an attempt has been made so that some hidden internal properties of the DNA sequence can be brought into light in order to identify coding regions from non-coding ones. In this approach the DNA sequence from various Homo Sapien genes have been identified for sample test and assigned numerical values based on weak-strong hydrogen bonding (WSHB) before application of digital signal analysis techniques. The statistical methodology applied for computation of Spectral content are simple and the Spectrum plots obtained show satisfactory results. Spectral analysis can be applied to study 
base-base correlation in DNA sequences. A key role is played by the mapping between nucleotides and real/complex numbers. In 2006, Galleani and Garello [36] presented a new approach where the mapping is not kept fixed: it is allowed to vary aiming to minimize the spectrum entropy, thus detecting the main hidden periodicities. The new technique is first introduced and discussed through a number of case studies, then extended to encompass time-frequency analysis.

For analyzing periodicities in categorical valued time series, the concept of the spectral envelope was introduced by Stoffer et al. [37] as a computationally simple and general statistical methodology for the harmonic analysis and scaling of non-numeric sequences. However, the spectral envelope methodology is computationally fast and simple because it is based on the fast Fourier transform and is nonparametric (i.e., it is model independent). This makes the methodology ideal for the analysis of long DNA sequences. Fourier analysis has been used in the analysis of correlated data (time series) since the turn of the century. Of fundamental interest in the use of Fourier techniques is the discovery of hidden periodicities or regularities in the data. Although Fourier analysis and related signal processing are well established in the physical sciences and engineering, they have only recently been applied in molecular biology. Since a DNA sequence can be regarded as a categorical-valued time series it is of interest to discover ways in which time series methodologies based on Fourier (or spectral) analysis can be applied to discover patterns in a long DNA sequence or similar patterns in two long sequences. Actually, the spectral envelope is an extension of spectral analysis when the data are categorical valued such as DNA sequences.

An algorithm for estimating the spectral envelope and the optimal scalings given a particular DNA sequence with alphabe $\xi=\left\{b_{1}, b_{2}, \ldots ., b_{r+1}\right\}$, is as follows [26].

(1) Given a DNA sequence of length $n$, from the $r \times 1$ vectors $Y_{t}, t=1,2, \ldots, n$; namely, for $j=1,2, \ldots, r, Y_{t}=e_{j}$ if $X_{t}=b_{j}$ where $e_{j}$ is a $r \times 1$ vector with a 1 in the $j$ th position as zeros elsewhere, and $Y_{t}=0$ if $X_{t}=b_{j+1}$.

(2) Calculate the Fast Fourier Transform FFT of the data, $d(j / n)=\sum_{t=1}^{n} Y_{t} \exp (-2 \pi i t j / n) / \sqrt{n}$.

Note that $d(j / n)$ is a $r \times 1$ complex-valued vector. Calculate the periodogram,

$$
\tilde{f}(j / n)=d(j / n) d^{*}(j / n), \quad \text { for } \quad j=1,2, \ldots,[n / 2], \quad \text { and }
$$

retain only the real part, say $f^{\sim r e}(j / n)$.

(3) Smooth the real part of the periodogram as preferred to obtain $f^{\sim r e}(j / n)$, a consistent estimator of the real part of the spectral matrix.

(4) Calculate the $r \times r$ variance-covariance matrix of the data, $S=\sum_{t=1}^{n}\left(Y_{t}-\bar{Y}\right)\left(Y_{t}-\bar{Y}\right)^{\prime} / n$, where $\bar{Y}$ is the sample mean of the data.

(5) For each $\omega=j / n, j=1,2, \ldots,[n / 2]$, determine the largest eigenvalue and the corresponding eigenvector of the matrix $2 S^{-1 / 2} f^{\sim r e}\left(\omega_{j}\right) S^{-1 / 2} / n$.

(6) The sample spectral envelope $\hat{\lambda}\left(\omega_{j}\right)$ is the eigenvalue obtained in the previous step.

(7) The optimal sample scaling is $\hat{\beta}\left(\omega_{j}\right)=S^{-1 / 2} v\left(\omega_{j}\right)$, where $v\left(\omega_{j}\right)$ the eigenvector obtained in the previous step.

In this paper, we discussed the discriminant analysis of the first, second, third and fourth eigenvalues of variance covariance matrix of Fast Fourier Transform (FFT) for numerical values representation of DNA sequences of five organisms, Human, E. coli, Rat, Wheat and Grasshopper. The analysis is based on three methods (All Variables, Forward Selection and Backward Selection) of discriminating. It should be noted that it is the first time that the variance covariance matrix eigenvalues of Fast Fourier Transform (FFT) for numerical values representation of DNA sequences, is used in an analysis like this and related analyzes.

\section{Discriminant Analysis}

Discriminant analysis aims to examine the dependence of one qualitative (classification) variable from several quantitative variables according to number of variations of qualitative variable we can distinction [38]). Actually, there is a discriminant analysis for two or more groups. The essential work of discriminant analysis is to get the optimal assigning rules that will minimize the likelihood of incorrect classification of elements. Every element is distinguished by some aspects which reflect its properties. This means that corresponding to measured characteristics; the examined elements are realizations of the random vector $X=\left(X_{1}, X_{2}, \ldots, X_{n}\right)$. The process starts with an analysis of group of elements in which is known relation to a specific group and also values of the random variables. The analysis result of the training set is to determine discriminant function that define the likelihood of classification of new unclassified element to certain group according to measured values. $x=\left(x_{1}, x_{2}, \ldots ., x_{m}\right)$ of its characteristics [39].

Two basic aims of discriminant analysis are stated by Stankovičová and Vojtková [38], the first aim is to find appropriate statistical way to distinguish between groups (Descriptive or analytical). The second aim is to include new statistical unit (object) that is recognized by a vector of $\mathrm{k}$ features to one of the based groups (Classification).

\section{Discriminant Analysis: Aims and Assumptions}

Discriminant analysis aims is offered by Meloun et al. [40].

(1) Define whether there are significant statistical differences among profiles of the average score of 
discriminators for two or more pre-defined classes.

(2) Define which of the discriminator is reflected the most in differential profiles of average score of two or more classes.

(3) Define procedures to involve objects into classes according to their score in discriminators set.

(4) Define the number of dimensions compilation of discrimination among classes created by a discriminators set.

Assumptions of discrimination model

(1) Multivariate normal distribution

conduct tests of significance of individual discriminatory variables and discriminatory functions are needful to assure this assumption. If the data is not distributed as multidimensional normal, then the results of classification are inaccurate. Moreover, the classification total error is not violated by Lack of performance of normal assumption because the classification error in one group may be overestimated and in the other group underestimated. [39]

(2) At least two groups must be there, with each case belonging to only one group so that the groups are independent and collectively exhaustive.

(3) Each group must be well defined and clearly distinguished from any one of groups.

(4) Before collecting the data, the groups should be well defined [41].

(5) Equality of variance-covariance within group.

(6) The covariance matrix within each group should be equal. Equality Test of Covariance Matrices can be used to verify it. When in doubt, try re-running the analyses using the Quadratic method, or by adding more observations or excluding one or two groups.
(7) Low multicollinearity of the variables

When high multicollinearity among two or more variables is present, the discriminant function coefficients will not reliably predict group membership. We can use the pooled within-groups correlation matrix to detect multicollinearity [42].

\section{Practical and Computational Steps for Discrimination and Classification}

In this section, we will introduce the discrimination and classification from practical and computational aspect.

\subsection{Discrimination Among Several Populations}

Suppose that we have $\mathrm{p}$ of populations, from the first population a sample $X_{1}, X_{2}, \ldots, X_{n_{1}}$ is drown, from the second population a sample $X_{n_{1}+1}, X_{n_{1}+2}, \ldots, X_{n_{1}+n_{2}}$ is drown and so on from the pth population a sample $X_{n_{1}+\ldots+n_{p-1}+1}, \ldots, X_{n_{T}}$, where $n_{1}+n_{2}+\ldots+n_{p}=n_{T}$. Let $\bar{X}_{j}$ be the sample mean for the population $\mathrm{j}, j=1, \ldots, p$, and $\bar{X}=\sum_{i=1}^{n_{T}} X_{i} / n_{T}$. Then the sample between matrix is,

$$
B=\sum_{j=1}^{p} n_{j}\left(\bar{X}_{j}-\bar{X}\right)\left(\bar{X}_{j}-\bar{X}\right)^{t}
$$

Thus,

$$
a^{t} B a=\sum_{j=1}^{p} n_{j} a^{t}\left(\bar{X}_{j}-\bar{X}\right)\left(\bar{X}_{j}-\bar{X}\right)^{t} a=\sum_{j=1}^{p} n_{j}\left(a^{t} \bar{X}_{j}-a^{t} \bar{X}\right)\left(\bar{X}_{j}^{t} a-\bar{X}^{t} a\right)=\sum_{j=1}^{p} n_{j}\left(\bar{Y}_{j}-\bar{Y}\right)^{2},
$$

$Y_{i}=a^{t} X_{i}, i=1, \ldots, n_{T}, \bar{Y}_{j}$ is the mean for the $\mathrm{j}$ 'th population, $j=1, \ldots, p$.

The sample within group matrix is

$$
W=\sum_{i=1}^{n_{1}}\left(X_{i}-\bar{X}_{1}\right)\left(X_{i}-\bar{X}_{1}\right)^{t}+\sum_{i=n_{1}+1}^{n_{1}+n_{2}}\left(X_{i}-\bar{X}_{2}\right)\left(X_{i}-\bar{X}_{2}\right)^{t}+\cdots+\sum_{i=n_{1}+\cdots n_{g-1}+1}^{n_{T}}\left(X_{i}-\bar{X}_{g}\right)\left(X_{i}-\bar{X}_{g}\right)^{t}
$$

Thus,

$$
\begin{gathered}
a^{t} W a=\sum_{i=1}^{n_{1}} a^{t}\left(X_{i}-\bar{X}_{1}\right)\left(X_{i}-\bar{X}_{1}\right)^{t} a+\cdots+\sum_{i=n_{1}+\ldots+n_{g-1}+1}^{n_{T}} a^{t}\left(X_{i}-\bar{X}_{p}\right)\left(X_{i}-\bar{X}_{p}\right)^{t} a \\
=\sum_{i=1}^{n_{1}}\left(Y_{i}-\bar{Y}_{1}\right)^{2}+\sum_{i=n_{1}+1}^{n_{1}+n_{2}}\left(Y_{i}-\bar{Y}_{2}\right)^{2}+\cdots+\sum_{i=n_{1}+\ldots+n_{g-1}+1}^{n_{T}}\left(Y_{i}-\bar{Y}_{g}\right)^{2}
\end{gathered}
$$

The pooled estimate based on $Y_{1}, Y_{2}, \ldots, Y_{n_{T}}$ is

$$
\frac{a^{t} W a}{n_{T}-p}=\frac{\sum_{i=1}^{n_{1}}\left(Y_{i}-\bar{Y}_{1}\right)^{2}+\sum_{i=n_{1}+1}^{n_{1}+n_{2}}\left(Y_{i}-\bar{Y}_{2}\right)^{2}+\ldots+\sum_{i=n_{1}+\ldots+n_{p-1}+1}^{n_{T}}\left(Y_{i}-\bar{Y}_{p}\right)^{2}}{n_{T}-g}
$$


The pooled estimate based on $X_{1}, X_{2}, \ldots, X_{n_{T}}$ is

$$
S_{\text {pooled }}=\frac{W}{n_{T}-p}=\frac{\sum_{i=1}^{n_{1}}\left(X_{i}-\bar{X}_{1}\right)\left(X_{i}-\bar{X}_{1}\right)^{t}+\cdots+\sum_{i=n_{1}+\ldots+n_{p-1}+1}^{n_{T}}\left(X_{i}-\bar{X}_{g}\right)\left(X_{i}-\bar{X}_{g}\right)^{t}}{n_{T}-p}
$$

Now we will present Fisher's linear discriminant method for several populations. Fisher's discriminant method for several populations is as follows steps,

Find the vector $\hat{a}_{1}$ maximizing the separation function

$$
S(a)=\frac{a^{t} B a}{a^{t} W a}=\frac{\sum_{j=1}^{p} n_{j}\left(\bar{Y}_{j}-\bar{Y}\right)^{2}}{\sum_{i=1}^{n_{1}}\left(Y_{i}-\bar{Y}_{1}\right)^{2}+\sum_{i=n_{1}+1}^{n_{1}+n_{2}}\left(Y_{i}-\bar{Y}_{2}\right)^{2}+\cdots+\sum_{i=n_{1}+\cdots+n_{g-1}+1}^{n_{T}}\left(Y_{i}-\bar{Y}_{g}\right)^{2}},
$$

subject to $\hat{a}_{1}^{t} S_{\text {pooled }} \hat{a}_{1}=1$.

The linear combination $\hat{a}_{1}^{t} X$ is called the sample first discriminant.

Find the vector $\hat{a}_{2}$ maximizing the separation function $S(a)$ subject to $\hat{a}_{2}^{t} S_{\text {pooled }} \hat{a}_{2}=1$ and $\hat{a}_{2}^{t} S_{\text {pooled }} \hat{a}_{1}=0$. So on,

Find the vector $\hat{a}_{s}$ maximizing the separation function $S(a)$ subject to $\hat{a}_{s}^{t} S_{\text {pooled }} \hat{a}_{s}=1$ and $\hat{a}_{s}^{t} S_{\text {pooled }} \hat{a}_{l}=0, l<s$.

Note that, $\hat{a}_{j}^{t} S_{\text {pooled }} \hat{a}_{j}$ is the estimate of $\operatorname{Var}\left(\hat{a}_{j}^{t} X\right), j=1, \ldots, s$ and $\hat{a}_{j}^{t} S_{\text {pooled }} \hat{a}_{l}, j \neq l$. is the estimate of $\operatorname{Cov}\left(\hat{a}_{j}^{t} X, \hat{a}_{l}^{t} X\right), j \neq l$.

The condition $\hat{a}_{j}^{t} S_{\text {pooled }} \hat{a}_{l}=0$ is like to the condition given in the principal component analysis.

Axiomatically, $S(a)$ measures the difference among the transformed means reverberated by $\sum_{j=1}^{p} n_{j}\left(\bar{Y}_{j}-\bar{Y}\right)^{2}$ close to the random variation of the transformed data reverberated by $\sum_{i=1}^{n_{1}}\left(Y_{i}-\bar{Y}_{1}\right)^{2}+\sum_{i=n_{1}+1}^{n_{1}+n_{2}}\left(Y_{i}-\bar{Y}_{2}\right)^{2}+\cdots+\sum_{i=n_{1}+\ldots+n_{g-1}+1}^{n_{T}}\left(Y_{i}-\bar{Y}_{k}\right)^{2}$. As the transformed observations $Y_{1}, Y_{2}, \ldots, Y_{n_{1}}$ (population $\left.\cdot 1\right)$, $Y_{n_{1}+1}, Y_{n_{1}+2}, \ldots, Y_{n_{1}+n_{2}}($ population $\cdot 2), \ldots, Y_{n_{1}+\ldots+n_{p-1}+1}$,

$$
\sum_{j=1}^{r}\left(\hat{Y}_{j}-\bar{Y}_{l}^{j}\right)^{2}=\sum_{j=1}^{r}\left[\hat{a}_{j}^{t}\left(X_{0}-\bar{X}_{l}\right)\right]^{2} \leq \sum_{j=1}^{r}\left[\hat{a}_{j}^{t}\left(X_{0}-\bar{X}_{i}\right)\right]^{2}=\sum_{j=1}^{r}\left(\hat{Y}_{j}-\bar{Y}_{i}^{j}\right)^{2}, i \neq l,
$$

Where, $\hat{Y}_{j}=\hat{a}_{j}^{t} X_{0}, \bar{Y}_{i}^{j}=\hat{a}_{j}^{t} \bar{X}_{i}, j=1, \ldots, r ; i=1, \ldots p$

Intuition of Fisher's method,

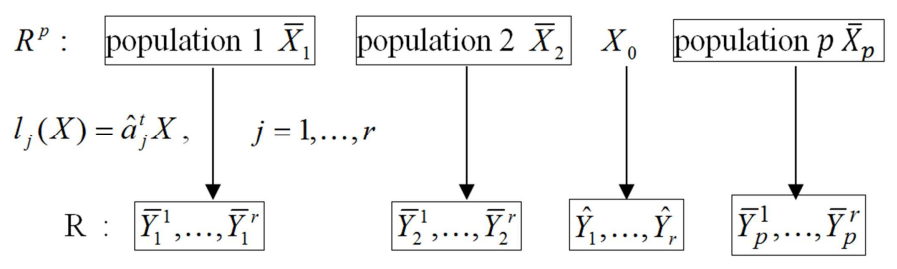


$\sum_{j=1}^{r}\left(\hat{Y}_{j}-\bar{Y}_{1}^{j}\right)^{2}:$ represent the total square distance between the transformed $X_{0}\left(\hat{Y}_{1}, \ldots, \hat{Y}_{r}\right)$ and the transformed mean of the first population $\left(\bar{Y}_{1}^{1}, \ldots, \bar{Y}_{1}^{r}\right)$.

$$
\sum_{j=1}^{r}\left(\hat{Y}_{j}-\bar{Y}_{2}^{j}\right)^{2}: \text { represent the total square distance }
$$

between the transformed $X_{0}\left(\hat{Y}_{1}, \ldots, \hat{Y}_{r}\right)$ and the transformed mean of the second population $\left(\bar{Y}_{2}^{1}, \ldots, \bar{Y}_{2}^{r}\right)$ and so on,

$$
\sum_{j=1}^{r}\left(\hat{Y}_{j}-\bar{Y}_{k}^{j}\right)^{2}: \text { represent the total square distance }
$$

between the transformed $\left(\hat{Y}_{1}, \ldots, \hat{Y}_{r}\right) X_{0}$ and the transformed mean of the $p t h$ population $\left(\bar{Y}_{p}^{1}, \ldots, \bar{Y}_{p}^{r}\right)$.

$$
\Rightarrow \sum_{j=1}^{r}\left(\hat{Y}_{j}-\bar{Y}_{l}^{j}\right)^{2} \leq \sum_{j=1}^{r}\left(\hat{Y}_{j}-\bar{Y}_{i}\right)^{2}, i \neq l \text {, imply the total }
$$

distance between the transformed $X_{0}$ and the transformed mean of the first population is smaller than the one between the one between the transformed $X_{0}$ and the transformed mean of the other populations. In another meaning, $X_{0}$ is closer to the first population than to the other populations. Therefore, $X_{0}$ is assigned to the first population.

\section{Stepwise Discriminant Analysis}

In stepwise discriminant analysis, large number of variables are entered, then with a series of steps, we are selected variables which discriminate the best and from them is created discriminant function. We can identify by some criteria how the stepwise discriminant analysis seeks at chosen of these variables (Stankovičová and Vojtková (2007) [38]).

(1) Forward selection: Variables come in into the discriminant function progressively and constantly is chosen the one that has the paramount profit in terms of discrimination. If this benefit is not statistically significant, no new variable enter into the function.

(2) Backward selection: here we get in all variables In the discriminant function and gradually are outcasted those whose removal does not case a statistically significant decrease rate of discrimination. When any other throw away would intend significant decrease in discrimination between groups, Then this process is completed.

(3) Stepwise selection: This chosen is mixing of the two past procedures. Here, enter new variables by degrees into discriminant function and it is always selection one with the utmost assist in terms of discrimination, while in every step is confirmed the possibility whether the variable would be eliminated and if eliminated variable does not have significant effect on decrease rate of discrimination [39].

Whatever, these procedures attain same outcomes but stipulation is that the input data have to be mutually uncorrelated. Otherwise if the correlation between input variables is significant, it is approperate to take Stepwise selection, where initially selected variable may be excluded in further steps because it is only correlation of other variables in the model. Criteria for making decision about enter of variable into the model or its elimination from the model avail following statistics. [40]

Wilks Lambda $(\lambda)$

The ratio of intra - group variability to the total variability represent Wilks $\lambda$ statistic. At every step is chosen the variable that satisfies the minimum value of this statistic. The significance of changes of Wilks criteria after discriminators submitting into the model or abstraction from the model is based on $F$ test criterion. The value of $F$ for change of Wilks criteria while adding discriminator into the model so that the model includes $\mathrm{p}$ discriminators is calculated as follows,

$$
F_{\text {zmeny }}=\frac{n-g-p}{g-1}\left[\frac{\frac{1-\lambda_{p+1}}{\lambda_{p}}}{\frac{\lambda_{p+1}}{\lambda_{p}}}\right]
$$

Where $p$ represent the number of discriminators in the model, $n$ represent the total number of objects, $g$ represent the number of classes, and $\lambda_{p}$ and $\lambda_{p+1}$ represent Wilks criterion before and after adding discriminators to the model respectively.

Härdle and Simar (2012) [43], derived Wilks lambda as follows,

$$
\Psi=\frac{S S_{\text {withn-groups }}}{S S_{\text {total }}}
$$

So the smaller value of $\Psi$ implies to more doubt upon the null hypothesis.

Determination the amount of variance in the grouping variable is interpreted by predictor variables by subtracting $\Psi$ from one [41].

\section{An Empirical Study}

The following algorithm steps is performed to achieve our aims.

Generate the DNA sequence for five organisms, Human, E. coli, Rat, Wheat and Grasshopper with corresponding information in table 1 .

Table 1. Relative proportions (\%) of Bases in DNA.

\begin{tabular}{lllll}
\hline Organisms & A & T & G & C \\
\hline Human & 30.9 & 29.4 & 19.9 & 19.8 \\
E. coli & 26.0 & 23.9 & 24.9 & 25.2 \\
Rat & 28.6 & 28.4 & 21.4 & 21.5 \\
Wheat & 27.3 & 27.1 & 22.7 & 22.8 \\
Grasshopper & 29.3 & 29.3 & 20.5 & 20.7 \\
\hline
\end{tabular}

The sequence size is $\mathrm{n}=500$ and run size is $\mathrm{k}=205$.

Transform DNA sequence to numerical values by setting one to the base that appears and zero to the other bases. 
Transform the sequence of numerical values to the corresponding FFT values.

Calculate the eigenvalues of variance covariance matrix for each run results, and then we get 205 fourth order vectors of eigenvalues for each organism. Each vector contains the four eigenvalues, rank from the largest one to the smallest.

All Variables, Forward Selection and Backward Selection methods of discrimination have been applied of the first, second, third and fourth variance- covariance matrix eigenvalues of Fast Fourier Transform (FFT) for numerical values representation of DNA sequences of five organisms, Human, E. coli, Rat, Wheat and Grasshopper. It should be noted that it is the first time that the variance covariance matrix eigenvalues of Fast Fourier Transform (FFT) for numerical values representation of DNA sequences, is used in an analysis like this and related analyzes.

For convenient, in the following discussions, we will refer to the organism by the first letter of his name.

\subsection{Results and Discussion}

Table 2. Eigenvalues and canonical correlation.

\begin{tabular}{|c|c|c|c|}
\hline Discriminant & Fironulu & Relative & Canonical \\
\hline Function & Eigenvalue & Percentage & Correlation \\
\hline 1 & 1.21447 & 75.87 & 0.74056 \\
\hline 2 & 0.357763 & 22.35 & 0.51332 \\
\hline 3 & 0.0262985 & 1.64 & 0.16008 \\
\hline 4 & 0.0021347 & 0.13 & 0.04615 \\
\hline
\end{tabular}

The three methods (All Variables, Forward Selection and Backward Selection) methods of discriminating are designed to develop a set of discriminating functions which can help predict $\mathrm{cf}$ based on the values of other quantitative variables. 1017 cases were used to develop a model to discriminate among the 5 levels of cf. Using a stepwise selection algorithm, it was determined that 4 variables were significant predictors of cf. That is, 4 predictor variables were entered. The 3 discriminating functions with P-values less than 0.05 are statistically significant at the $95.0 \%$ confidence level.

Table 3. Wilks lambda and P-value.

\begin{tabular}{lllll}
\hline Functions & Wilks & & & \\
\hline Derived & Lambda & Chi-Square & DF & P-Value \\
\hline 1 & 0.323375 & 1141.9250 & 16 & 0.0000 \\
2 & 0.716104 & 337.7694 & 9 & 0.0000 \\
3 & 0.9723 & 28.4141 & 4 & 0.0000 \\
4 & 0.99787 & 2.1569 & 1 & 0.1419 \\
\hline
\end{tabular}

When we use the forward selection method for the stepwise regression, we consider the following:

F-to-enter: 4.0

F-to-remove: 4.0

Step 0:

0 variables in the model.

Step 1:

Adding variable 3 with F-to-enter $=189.851$

1 variables in the model.

Wilk's lambda $=0.571298$ Approximate $\mathrm{F}=189.851$ with
$\mathrm{P}$-value $=0.0000$

Step 2:

Adding variable 4 with F-to-enter $=65.601$

2 variables in the model.

Wilk's lambda $=0.453574$ Approximate $\mathrm{F}=122.54$ with

P-value $=0.0000$

Step 3:

Adding variable 2 with F-to-enter $=10.9635$

3 variables in the model.

Wilk's lambda $=0.434699$ Approximate $\mathrm{F}=82.424$ with

$\mathrm{P}$-value $=0.0000$

Step 4:

Adding variable 1 with F-to-enter $=86.8387$

4 variables in the model.

Wilk's lambda $=0.323375$ Approximate $\mathrm{F}=86.1478$ with P-value $=0.0000$

Final model selected.

and when we use the backward selection method for the stepwise regression, we consider the following:

F-to-enter: 4.0

F-to-remove: 4.0

Step 0:

4 variables in the model.

Wilk's lambda $=0.323375$ Approximate $F=86.1478$ with $\mathrm{P}$-value $=0.0000$

Final model selected.

The following Classification Function Coefficients for cf shows the functions used to classify observations. There is a function for each of the 5 levels of cf. For example, the function used for the first level of $\mathrm{cf}$ is

$-263305 .+1054.3 * 1+1051.03 * 2+1052.79 * 3+$ $1054.87 * 4$

These functions are used to predict which level of cf new observations belong to.

Table 4. Classification Function Coefficients for cf of each of five organisms.

\begin{tabular}{llllll}
\hline & $\boldsymbol{e}$ & $\boldsymbol{g}$ & $\boldsymbol{h}$ & $\boldsymbol{r}$ & $\boldsymbol{w}$ \\
\hline 1 & 1054.3 & 1052.06 & 1054.39 & 1053.32 & 1052.99 \\
2 & 1051.03 & 1048.78 & 1051.12 & 1049.96 & 1049.65 \\
3 & 1052.79 & 1050.27 & 1052.53 & 1051.6 & 1051.38 \\
4 & 1054.87 & 1052.4 & 1054.71 & 1053.72 & 1053.49 \\
CONSTANT & -263305 & -262129 & -263284 & -262760 & -262621 \\
\hline
\end{tabular}

The classification function coefficients for cf in table 4, shows the functions used to classify observations. There is a function for each of the 5 levels of cf. For example, the function used for the first level of $\mathrm{cf}$ is

$$
-263305 \text {. }+1054.3 * 1+1051.03 * 2+1052.79 * 3+
$$
$1054.87 * 4$

These functions are used to predict which level of $\mathrm{cf}$ new observations belong to.

Table 5. Discriminant Function Coefficients for cf of each of five organisms.

\begin{tabular}{lllll}
\hline & $\mathbf{1}$ & $\mathbf{2}$ & $\mathbf{3}$ & $\mathbf{4}$ \\
\hline 1 & -1.42552 & 10.3929 & -2.29605 & -0.837972 \\
2 & -1.20084 & 9.37211 & -0.758743 & -0.578266 \\
3 & -1.85225 & 8.41815 & -1.2011 & -1.29646 \\
4 & -1.88923 & 9.5499 & -1.61871 & 0.0991884 \\
\hline
\end{tabular}


Unstandardized Coefficients

\begin{tabular}{lllll}
\hline & $\mathbf{1}$ & $\mathbf{2}$ & $\mathbf{3}$ & $\mathbf{4}$ \\
\hline 1 & -0.192768 & 1.4054 & -0.310486 & -0.113316 \\
2 & -0.183743 & 1.43404 & -0.116096 & -0.0884812 \\
3 & -0.306698 & 1.39389 & -0.198879 & -0.214669 \\
4 & -0.27933 & 1.41199 & -0.239333 & 0.0146654 \\
CONSTANT & 117.068 & -705.273 & 108.875 & 51.6442 \\
\hline
\end{tabular}

The discriminant function coefficients for cf in table 5, shows the coefficients of the functions used to discriminate amongst the different levels of cf. Of particular interest are the standardized coefficients. The first standardized discriminating function is

$-1.42552 * 1-1.20084 * 2-1.85225 * 3-1.88923 * 4$

From the relative magnitude of the coefficients in the above equation, you can determine how the independent variables are being used to discriminate amongst the groups.

The following Classification Table 6 shows the results of using the derived discriminant functions to classify observations. It lists the two highest scores amongst the classification functions for each of the 1017 observations used to fit the model, as well as for any new observations. For example, row 1 scored highest for $\mathrm{cf}=\mathrm{e}$ and second highest for $\mathrm{cf}=\mathrm{w}$. In fact, the true value of $\mathrm{cf}$ was e. Amongst the 1017 observations used to fit the model, 583 or $57.3255 \%$ were correctly classified. You can predict additional observations by adding new rows to the current data file, filling in values for each of the independent variables but leaving the cell for cf blank.

Table 6. Classification Table of each of five organisms.

\begin{tabular}{|c|c|c|c|c|c|c|}
\hline Actual & Group & Predicted & cf & & & \\
\hline ef & Size & e & g & h & $\mathbf{r}$ & $\mathbf{w}$ \\
\hline $\mathrm{e}$ & 203 & $\begin{array}{l}168 \\
(-82.76 \%)\end{array}$ & $\begin{array}{l}0 \\
(0.00 \%)\end{array}$ & $\begin{array}{l}1 \\
(-0.49 \%)\end{array}$ & $\begin{array}{l}29 \\
(-14.29 \%)\end{array}$ & $\begin{array}{l}5 \\
(-2.46 \%)\end{array}$ \\
\hline $\mathrm{g}$ & 203 & $\begin{array}{l}9 \\
(-4.43 \%)\end{array}$ & $\begin{array}{l}115 \\
(-56.65 \%)\end{array}$ & $\begin{array}{l}41 \\
(-20.20 \%)\end{array}$ & $\begin{array}{l}22 \\
(-10.84 \%)\end{array}$ & $\begin{array}{l}16 \\
(-7.88 \%)\end{array}$ \\
\hline $\mathrm{h}$ & 205 & $\begin{array}{l}8 \\
(-3.90 \%)\end{array}$ & $\begin{array}{l}0 \\
(0.00 \%\end{array}$ & $\begin{array}{l}168 \\
(-81.95 \%)\end{array}$ & $\begin{array}{l}29 \\
(-14.15 \%)\end{array}$ & $\begin{array}{l}0 \\
(0.00 \%)\end{array}$ \\
\hline r & 203 & $\begin{array}{l}33 \\
(-16.26 \%)\end{array}$ & $\begin{array}{l}37 \\
(-18.23 \%)\end{array}$ & $\begin{array}{l}36 \\
(-17.73 \%)\end{array}$ & $\begin{array}{l}57 \\
(-28.08 \%)\end{array}$ & $\begin{array}{l}40 \\
(-19.70 \%)\end{array}$ \\
\hline $\mathrm{w}$ & 203 & $\begin{array}{l}68 \\
(-33.50 \%)\end{array}$ & $\begin{array}{l}14 \\
(-6.90 \%)\end{array}$ & $\begin{array}{l}6 \\
(-2.96 \%)\end{array}$ & $\begin{array}{l}40 \\
(-19.70 \%)\end{array}$ & $\begin{array}{l}75 \\
(-36.95 \%)\end{array}$ \\
\hline
\end{tabular}

Percent of cases correctly classified: $57.33 \%$

Table 7. Group Centroids for cf of each of five organisms.

\begin{tabular}{lllll}
\hline Group & $\mathbf{1}$ & $\mathbf{2}$ & $\mathbf{3}$ & $\mathbf{4}$ \\
\hline $\mathrm{e}$ & -1.52919 & 0.456441 & 0.172723 & -0.0272532 \\
$\mathrm{~g}$ & 1.09833 & -0.772067 & 0.179081 & -0.0154093 \\
$\mathrm{~h}$ & 1.31789 & 0.874488 & -0.0143922 & 0.0279504 \\
$\mathrm{r}$ & -0.0312728 & -0.132379 & -0.246469 & -0.0589958 \\
$\mathrm{w}$ & -0.868747 & -0.435099 & -0.0908001 & 0.0734325 \\
\hline
\end{tabular}

The group centroids for $\mathrm{cf}$ in table 7 , shows the average values of each of the 4 discriminant functions for each of the 5 values of $\mathrm{cf}$.

The following summary statistics by group in table 8 , shows the averages and standard deviations of each independent variable for each level of $\mathrm{cf}$.

Table 8. Summary Statistics by Group of each of five organisms.

\begin{tabular}{lllllll}
\hline f & $\mathbf{e}$ & $\mathbf{G}$ & $\mathbf{h}$ & $\mathbf{r}$ & w & TOTAL \\
\hline COUNTS & 203 & 203 & 205 & 203 & 203 & 1017 \\
MEANS & & & & & & \\
1 & 139.002 & 152.004 & 154.26 & 148.687 & 143.425 & 147.489 \\
2 & 129.323 & 138.523 & 141.248 & 132.763 & 129.461 & 134.277 \\
3 & 121.549 & 110.033 & 107.429 & 114.702 & 118.538 & 114.436 \\
4 & 110.127 & 98.3395 & 97.0624 & 103.335 & 107.925 & 103.345 \\
STD. DEVIATIONS & & & & & & \\
1 & 6.22749 & 7.05805 & 7.31945 & 9.22462 & 6.79524 & 9.26124 \\
2 & 4.12905 & 7.57472 & 6.97772 & 7.73094 & 5.53362 & 8.12094 \\
3 & 4.66854 & 7.38305 & 6.3962 & 6.47941 & 4.80889 & 7.97446 \\
4 & 6.93967 & 6.62588 & 6.36103 & 7.53226 & 6.28599 & 8.48025 \\
\hline
\end{tabular}

Table 9. Pooled Within-Group Statistics for cf of each of five organisms. Within-Group Covariance Matrix

\begin{tabular}{lllll}
\hline & $\mathbf{1}$ & $\mathbf{2}$ & $\mathbf{3}$ & $\mathbf{4}$ \\
\hline 1 & 54.686 & -3.04941 & -22.4781 & -29.0527 \\
2 & -3.04941 & 42.7123 & -18.3195 & -21.103 \\
3 & -22.4781 & -18.3195 & 36.4736 & 4.43221 \\
4 & -29.0527 & -21.103 & 4.43221 & 45.7441 \\
\hline
\end{tabular}

\begin{tabular}{lllll}
\hline & $\mathbf{1}$ & $\mathbf{2}$ & $\mathbf{3}$ & $\mathbf{4}$ \\
\hline 1 & 1 & -0.0630959 & -0.503306 & -0.580872 \\
2 & -0.0630959 & 1 & -0.464138 & -0.477419 \\
3 & -0.503306 & -0.464138 & 1 & 0.108508 \\
4 & -0.580872 & -0.477419 & 0.108508 & 1 \\
\hline
\end{tabular}

In addition, the following pooled within-group statistics for cf in table 9, shows the estimated correlations between the independent variables within each group. The within group information from all of the groups has been pooled. 
This can be seen in figure 2 down.
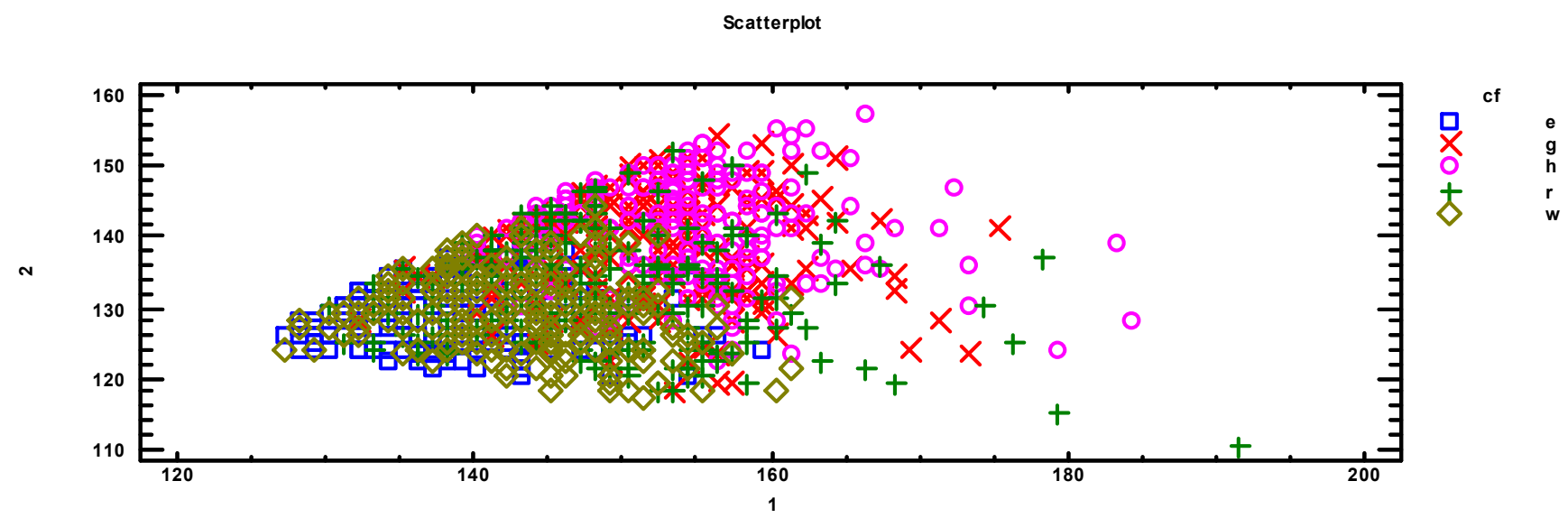

(a)

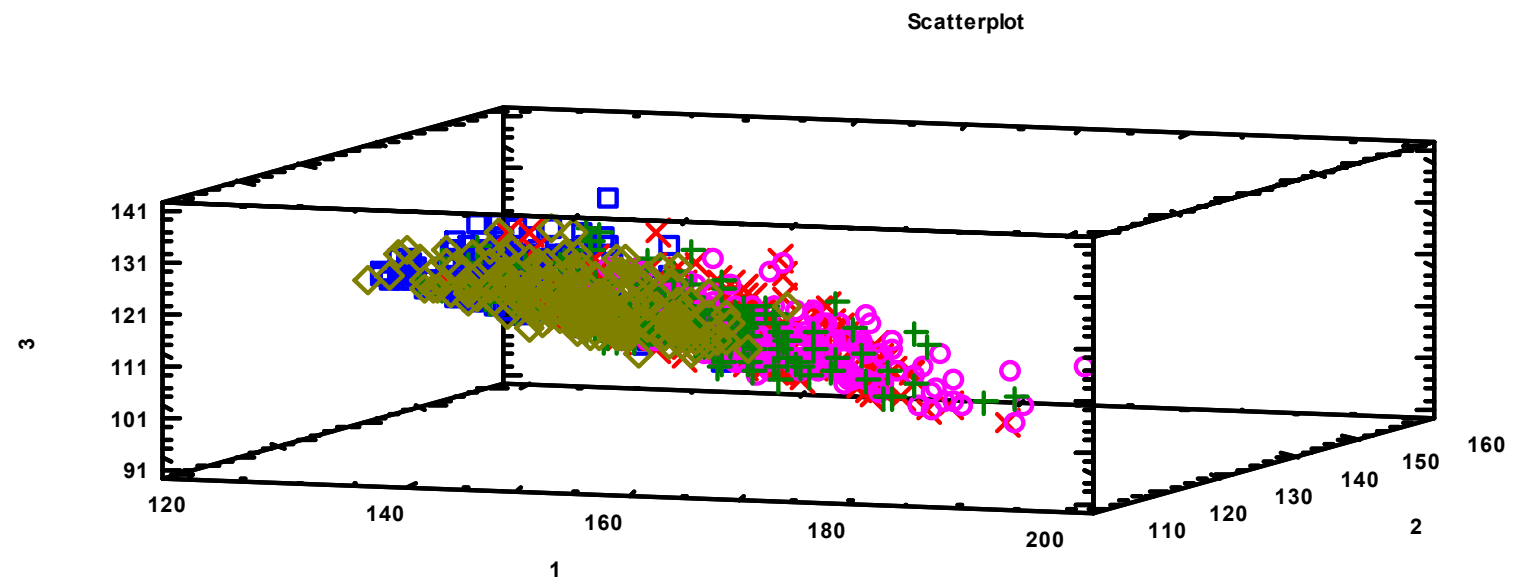

(b)

Plot of Discriminant Functions

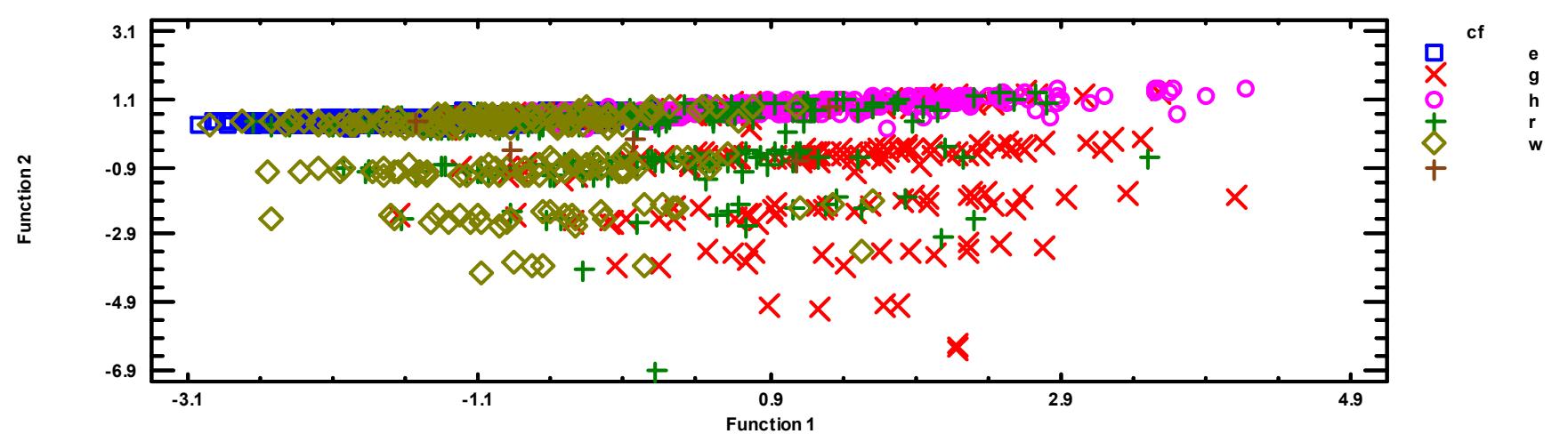

(c)

Figure 2. Plots of: (a) Two dimension scatter plot, (b) Three dimension scatter plot, (c) Discriminant functions.

\section{Summary}

Functions have been reached whereby a discrimination is made among organisms according to eigenvalues of variance covariance matrix of FFT for numerical values representation of DNA sequences, and then classify any other observation to any of organisms belong.
The methods used here are aimed to discriminant among different organisms using another point of view. This point of view is based on eigenvalues of variance covariance matrix of FFT for numerical values representation of DNA sequences. It should be noted that, it is the first time this point of view is used to achieve aims like ours.

Empirical studies are conducted to show the value of our 
point of view and the applications based on. Therefore, we recommended that,

1. Other empirical studies should be done for other organisms and statistical methods by using the point of view adopted here.

2. Aspects stated here must be used in an applied manner for DNA sequences discrimination.

\section{Appendix}

Table A1. Actual and highest two groups for each observation.

\begin{tabular}{|c|c|c|c|c|c|c|c|c|c|}
\hline \multirow{2}{*}{ Row } & \multirow{2}{*}{$\begin{array}{l}\text { Actual } \\
\text { Group } \\
\end{array}$} & \multirow{2}{*}{$\begin{array}{l}\text { Highest } \\
\text { Group }\end{array}$} & \multirow{2}{*}{$\begin{array}{l}\text { Highest } \\
\text { Value }\end{array}$} & \multirow{2}{*}{$\begin{array}{l}\text { Squared } \\
\text { Distance }\end{array}$} & \multirow{2}{*}{ Prob. } & \multirow{2}{*}{$\begin{array}{l}\text { 2nd Highest } \\
\text { Group } \\
\end{array}$} & \multirow{2}{*}{$\begin{array}{l}\text { 2nd Highest } \\
\text { Value }\end{array}$} & \multirow{2}{*}{$\begin{array}{l}\text { Squared } \\
\text { Distance }\end{array}$} & \multirow{2}{*}{ Prob. } \\
\hline & & & & & & & & & \\
\hline 1 & $\mathrm{e}$ & $\mathrm{e}$ & 263318 & 2.32255 & 0.7162 & w & 263317 & 4.54363 & 0.2359 \\
\hline 2 & $\mathrm{e}$ & $\mathrm{e}$ & 263286 & 0.611535 & 0.5394 & $\mathrm{w}$ & 263285 & 2.06059 & 0.2614 \\
\hline 3 & $\mathrm{e}$ & $\mathrm{e}$ & 263306 & 2.52435 & 0.7935 & w & 263305 & 5.50989 & 0.1783 \\
\hline 4 & e & $\mathrm{e}$ & 263323 & 1.59725 & 0.5233 & w & 263323 & 2.50057 & 0.3331 \\
\hline 5 & $\mathrm{e}$ & $\mathrm{e}$ & 263307 & 0.329547 & 0.5967 & w & 263307 & 1.79854 & 0.2863 \\
\hline 6 & e & e & 263301 & 1.51209 & 0.6882 & w & 263299 & 3.65553 & 0.2356 \\
\hline 7 & $\mathrm{e}$ & $*_{\mathrm{r}}$ & 263311 & 1.38723 & 0.3531 & w & 263311 & 1.65234 & 0.3092 \\
\hline 8 & $\mathrm{e}$ & $\mathrm{e}$ & 263287 & 0.756714 & 0.6499 & w & 263286 & 2.77045 & 0.2374 \\
\hline 9 & $\mathrm{e}$ & $\mathrm{e}$ & 263296 & 0.280903 & 0.6548 & w & 263295 & 2.22558 & 0.2477 \\
\hline 10 & e & e & 263304 & 0.303498 & 0.6662 & w & 263303 & 2.2509 & 0.2516 \\
\hline 11 & e & e & 263322 & 3.24033 & 0.7671 & w & 263321 & 5.88307 & 0.2047 \\
\hline 12 & e & $\mathrm{e}$ & 263294 & 1.85343 & 0.5933 & w & 263293 & 3.50248 & 0.2601 \\
\hline 13 & $\mathrm{e}$ & $\mathrm{e}$ & 263323 & 3.82238 & 0.7813 & w & 263322 & 6.60322 & 0.1945 \\
\hline 14 & $\mathrm{e}$ & $\mathrm{e}$ & 263316 & 0.694525 & 0.6521 & w & 263315 & 2.44216 & 0.2722 \\
\hline 15 & $\mathrm{e}$ & $\mathrm{e}$ & 263306 & 0.570849 & 0.3741 & w & 263305 & 0.916633 & 0.3147 \\
\hline 16 & $\mathrm{e}$ & $\mathrm{e}$ & 263301 & 1.14726 & 0.6362 & w & 263301 & 2.94301 & 0.2592 \\
\hline 17 & e & e & 263306 & 2.33252 & 0.807 & w & 263304 & 5.46231 & 0.1688 \\
\hline 18 & e & e & 263307 & 0.44653 & 0.6718 & $\mathrm{w}$ & 263306 & 2.40104 & 0.2528 \\
\hline 19 & $\mathrm{e}$ & $\mathrm{e}$ & 263299 & 1.14912 & 0.5835 & w & 263298 & 2.62183 & 0.2794 \\
\hline 20 & $\mathrm{e}$ & $\mathrm{e}$ & 263307 & 2.36445 & 0.741 & w & 263306 & 4.85805 & 0.213 \\
\hline 21 & $\mathrm{e}$ & e & 263267 & 3.88883 & 0.5018 & $\mathrm{w}$ & 263266 & 5.41709 & 0.2337 \\
\hline 22 & $\mathrm{e}$ & $\mathrm{e}$ & 263318 & 2.83505 & 0.7333 & w & 263317 & 5.19423 & 0.2254 \\
\hline 23 & e & e & 263298 & 2.55544 & 0.546 & w & 263297 & 3.92338 & 0.2755 \\
\hline 24 & e & $\mathrm{e}$ & 263310 & 0.230065 & 0.5876 & w & 263309 & 1.62754 & 0.2922 \\
\hline 25 & $\mathrm{e}$ & $\mathrm{e}$ & 263282 & 1.14422 & 0.458 & w & 263281 & 2.30997 & 0.2557 \\
\hline 26 & $\mathrm{e}$ & $\mathrm{e}$ & 263315 & 1.58014 & 0.6668 & w & 263314 & 3.45231 & 0.2615 \\
\hline 27 & e & $\mathrm{e}$ & 263296 & 0.709799 & 0.6838 & w & 263295 & 2.85819 & 0.2336 \\
\hline 28 & $\mathrm{e}$ & $\mathrm{e}$ & 263321 & 1.8433 & 0.7198 & w & 263320 & 4.07177 & 0.2362 \\
\hline 29 & $\mathrm{e}$ & $\mathrm{e}$ & 263294 & 0.915504 & 0.7313 & w & 263293 & 3.41748 & 0.2093 \\
\hline 30 & e & e & 263293 & 1.66903 & 0.3331 & $\mathrm{r}$ & 263292 & 2.11359 & 0.2667 \\
\hline 31 & $\mathrm{e}$ & $\mathrm{e}$ & 263290 & 0.675837 & 0.4885 & w & 263289 & 1.84403 & 0.2724 \\
\hline 32 & $\mathrm{e}$ & $\mathrm{e}$ & 263293 & 0.655956 & 0.6928 & w & 263292 & 2.88175 & 0.2277 \\
\hline 33 & $\mathrm{e}$ & $\mathrm{e}$ & 263282 & 1.69514 & 0.555 & w & 263282 & 3.22829 & 0.2579 \\
\hline 34 & e & $* \mathrm{r}$ & 263287 & 1.19922 & 0.3004 & e & 263287 & 1.26536 & 0.2906 \\
\hline 35 & e & e & 263312 & 3.15163 & 0.7894 & w & 263310 & 6.06688 & 0.1838 \\
\hline 36 & e & $* \mathrm{r}$ & 263294 & 0.766822 & 0.3471 & $\mathrm{w}$ & 263294 & 1.61339 & 0.2273 \\
\hline 37 & $\mathrm{e}$ & e & 263277 & 2.24763 & 0.6094 & w & 263276 & 4.127 & 0.2381 \\
\hline 38 & e & $\mathrm{e}$ & 263306 & 1.05394 & 0.6859 & w & 263305 & 3.13326 & 0.2425 \\
\hline 39 & $\mathrm{e}$ & $\mathrm{e}$ & 263276 & 8.59582 & 0.4498 & w & 263276 & 9.66047 & 0.2641 \\
\hline 40 & $\mathrm{e}$ & $\mathrm{e}$ & 263288 & 1.3139 & 0.6103 & w & 263288 & 3.05912 & 0.255 \\
\hline 41 & e & e & 263322 & 1.29199 & 0.4453 & w & 263321 & 1.78103 & 0.3487 \\
\hline 42 & $\mathrm{e}$ & $\mathrm{e}$ & 263287 & 2.3495 & 0.3946 & w & 263286 & 3.22796 & 0.2543 \\
\hline 43 & $\mathrm{e}$ & $\mathrm{e}$ & 263289 & 1.80866 & 0.3141 & $\mathrm{r}$ & 263289 & 2.08926 & 0.273 \\
\hline 44 & $\mathrm{e}$ & $*_{\mathrm{W}}$ & 263335 & 3.603 & 0.3899 & e & 263335 & 3.86512 & 0.342 \\
\hline 45 & e & e & 263322 & 1.51194 & 0.6756 & $\mathrm{w}$ & 263321 & 3.39272 & 0.2638 \\
\hline 46 & e & $*_{\mathrm{r}}$ & 263285 & 4.44316 & 0.401 & w & 263284 & 5.51328 & 0.2348 \\
\hline 47 & e & $*_{\mathrm{w}}$ & 263323 & 2.26932 & 0.3534 & e & 263323 & 2.27222 & 0.3529 \\
\hline 48 & $\mathrm{e}$ & e & 263326 & 1.7479 & 0.4799 & w & 263326 & 2.37626 & 0.3505 \\
\hline 49 & $\mathrm{e}$ & $*_{\mathrm{r}}$ & 263290 & 2.23961 & 0.3633 & e & 263289 & 2.92666 & 0.2577 \\
\hline 50 & $\mathrm{e}$ & $\mathrm{e}$ & 263287 & 1.19163 & 0.7155 & w & 263286 & 3.6258 & 0.2118 \\
\hline 51 & $\mathrm{e}$ & $\mathrm{e}$ & 263307 & 0.585495 & 0.5783 & w & 263307 & 1.96943 & 0.2895 \\
\hline 52 & e & $*_{\mathrm{r}}$ & 263292 & 1.25049 & 0.3355 & $\mathrm{~h}$ & 263292 & 1.70278 & 0.2676 \\
\hline 53 & e & $* \mathrm{r}$ & 263310 & 1.33908 & 0.4061 & w & 263309 & 2.71064 & 0.2045 \\
\hline 54 & $\mathrm{e}$ & $\mathrm{e}$ & 263288 & 1.05333 & 0.7146 & w & 263287 & 3.48134 & 0.2122 \\
\hline
\end{tabular}




\begin{tabular}{|c|c|c|c|c|c|c|c|c|c|}
\hline \multirow{2}{*}{ Row } & \multirow{2}{*}{$\begin{array}{l}\text { Actual } \\
\text { Group }\end{array}$} & \multirow{2}{*}{$\begin{array}{l}\text { Highest } \\
\text { Group }\end{array}$} & \multirow{2}{*}{$\begin{array}{l}\text { Highest } \\
\text { Value }\end{array}$} & \multirow{2}{*}{$\frac{\text { Squared }}{\text { Distance }}$} & \multirow{2}{*}{ Prob. } & \multirow{2}{*}{$\begin{array}{l}\text { 2nd Highest } \\
\text { Group }\end{array}$} & \multirow{2}{*}{$\begin{array}{l}\text { 2nd Highest } \\
\text { Value }\end{array}$} & \multirow{2}{*}{$\begin{array}{l}\text { Squared } \\
\text { Distance }\end{array}$} & \multirow{2}{*}{ Prob. } \\
\hline & & & & & & & & & \\
\hline 55 & $\mathrm{e}$ & $*^{r}$ & 263296 & 1.45779 & 0.3339 & $\mathrm{e}$ & 263296 & 1.72554 & 0.292 \\
\hline 56 & e & $* \mathrm{r}$ & 263298 & 2.5653 & 0.3045 & $\mathrm{w}$ & 263298 & 3.00824 & 0.244 \\
\hline 57 & e & e & 263293 & 0.630536 & 0.569 & $\mathrm{w}$ & 263292 & 2.14739 & 0.2665 \\
\hline 58 & e & $* \mathrm{r}$ & 263265 & 3.98211 & 0.3049 & $\mathrm{e}$ & 263265 & 4.13897 & 0.2819 \\
\hline 59 & e & $\mathrm{e}$ & 263307 & 0.428474 & 0.5724 & $\mathrm{w}$ & 263306 & 1.75938 & 0.2942 \\
\hline 60 & $\mathrm{e}$ & $\mathrm{e}$ & 263278 & 3.52538 & 0.3759 & $\mathrm{r}$ & 263277 & 4.0931 & 0.283 \\
\hline 61 & $\mathrm{e}$ & $\mathrm{e}$ & 263298 & 2.05163 & 0.3766 & $\mathrm{w}$ & 263298 & 2.48003 & 0.304 \\
\hline 62 & $\mathrm{e}$ & e & 263305 & 0.242478 & 0.4423 & $\mathrm{w}$ & 263304 & 0.935955 & 0.3127 \\
\hline 63 & $\mathrm{e}$ & $\mathrm{e}$ & 263312 & 1.41194 & 0.3452 & w & 263312 & 1.54317 & 0.3233 \\
\hline 64 & $\mathrm{e}$ & $\mathrm{e}$ & 263315 & 2.39604 & 0.7629 & w & 263313 & 5.03633 & 0.2038 \\
\hline 65 & e & $*_{\mathrm{r}}$ & 263318 & 2.55336 & 0.4871 & $\mathrm{w}$ & 263317 & 4.06385 & 0.2289 \\
\hline 66 & e & e & 263319 & 0.79105 & 0.5421 & $\mathrm{w}$ & 263319 & 1.8374 & 0.3213 \\
\hline 67 & e & $\mathrm{e}$ & 263305 & 0.194699 & 0.4709 & $\mathrm{w}$ & 263305 & 1.02627 & 0.3107 \\
\hline 68 & $\mathrm{e}$ & e & 263289 & 0.77199 & 0.424 & $\mathrm{w}$ & 263288 & 1.60482 & 0.2796 \\
\hline 69 & e & $*_{\mathrm{r}}$ & 263290 & 2.38 & 0.3022 & $\mathrm{w}$ & 263290 & 3.14839 & 0.2058 \\
\hline 70 & $\mathrm{e}$ & $\mathrm{e}$ & 263295 & 1.78155 & 0.4839 & $\mathrm{w}$ & 263295 & 2.76725 & 0.2956 \\
\hline 71 & e & $\mathrm{e}$ & 263301 & 2.26304 & 0.5289 & $\mathrm{w}$ & 263300 & 3.49411 & 0.2858 \\
\hline 72 & $\mathrm{e}$ & $\mathrm{e}$ & 263300 & 0.0594097 & 0.4986 & w & 263299 & 1.09936 & 0.2964 \\
\hline 73 & $\mathrm{e}$ & $\mathrm{e}$ & 263327 & 1.51277 & 0.6014 & $\mathrm{w}$ & 263326 & 2.84391 & 0.3091 \\
\hline 74 & $\mathrm{e}$ & $* \mathrm{r}$ & 263293 & 0.933136 & 0.3556 & $\mathrm{w}$ & 263292 & 1.61701 & 0.2526 \\
\hline 75 & e & e & 263313 & 2.54073 & 0.7838 & $\mathrm{w}$ & 263312 & 5.39063 & 0.1885 \\
\hline 76 & $\mathrm{e}$ & $\mathrm{e}$ & 263311 & 0.55169 & 0.4714 & $\mathrm{w}$ & 263311 & 1.31297 & 0.3222 \\
\hline 77 & $\mathrm{e}$ & e & 263314 & 0.556485 & 0.5101 & $\mathrm{w}$ & 263313 & 1.4694 & 0.3232 \\
\hline 78 & e & $\mathrm{e}$ & 263335 & 2.65766 & 0.566 & w & 263334 & 3.7089 & 0.3346 \\
\hline 79 & $\mathrm{e}$ & $* \mathrm{r}$ & 263254 & 10.3034 & 0.346 & $\mathrm{e}$ & 263253 & 11.066 & 0.2363 \\
\hline 80 & $\mathrm{e}$ & $*_{\mathrm{r}}$ & 263314 & 2.5466 & 0.4736 & $\mathrm{w}$ & 263314 & 3.8423 & 0.2478 \\
\hline 81 & e & $* \mathrm{r}$ & 263303 & 2.51479 & 0.3309 & $\mathrm{w}$ & 263302 & 3.19855 & 0.2351 \\
\hline 82 & $\mathrm{e}$ & e & 263313 & 1.51124 & 0.4969 & $\mathrm{w}$ & 263312 & 2.40471 & 0.3179 \\
\hline 83 & e & $*_{\mathrm{r}}$ & 263337 & 5.57066 & 0.5084 & $\mathrm{w}$ & 263336 & 7.4 & 0.2037 \\
\hline 84 & e & e & 263318 & 1.23402 & 0.6295 & w & 263317 & 2.83123 & 0.2833 \\
\hline 85 & e & $\mathrm{e}$ & 263328 & 1.98278 & 0.6008 & w & 263327 & 3.30775 & 0.3097 \\
\hline 86 & e & $\mathrm{e}$ & 263270 & 4.96895 & 0.6935 & $\mathrm{w}$ & 263269 & 7.41056 & 0.2046 \\
\hline 87 & $\mathrm{e}$ & $\mathrm{e}$ & 263304 & 0.454412 & 0.5703 & $\mathrm{w}$ & 263303 & 1.83712 & 0.2857 \\
\hline 88 & $\mathrm{e}$ & $\mathrm{e}$ & 263303 & 0.317217 & 0.4497 & $\mathrm{w}$ & 263303 & 1.07604 & 0.3077 \\
\hline 89 & $\mathrm{e}$ & e & 263306 & 1.43259 & 0.7054 & $\mathrm{w}$ & 263305 & 3.65 & 0.2328 \\
\hline 90 & $\mathrm{e}$ & $*_{\mathrm{r}}$ & 263307 & 1.01706 & 0.373 & $\mathrm{w}$ & 263306 & 1.77899 & 0.2549 \\
\hline 91 & $\mathrm{e}$ & e & 263282 & 1.632 & 0.6436 & $\mathrm{w}$ & 263281 & 3.65068 & 0.2346 \\
\hline 92 & $\mathrm{e}$ & e & 263299 & 0.259963 & 0.5343 & $\mathrm{w}$ & 263299 & 1.50335 & 0.287 \\
\hline 93 & $\mathrm{e}$ & e & 263270 & 7.14301 & 0.6126 & $\mathrm{w}$ & 263269 & 9.10526 & 0.2297 \\
\hline 94 & $\mathrm{e}$ & $\mathrm{e}$ & 263313 & 2.24836 & 0.3934 & $\mathrm{w}$ & 263313 & 2.54358 & 0.3394 \\
\hline 95 & $\mathrm{e}$ & $\mathrm{e}$ & 263309 & 0.908499 & 0.6704 & $\mathrm{w}$ & 263308 & 2.85096 & 0.2538 \\
\hline 96 & e & $*_{\mathrm{h}}$ & 263286 & 1.26569 & 0.4013 & $\mathrm{r}$ & 263285 & 1.70775 & 0.3217 \\
\hline 97 & $\mathrm{e}$ & $*_{\mathrm{r}}$ & 263344 & 5.70577 & 0.3943 & w & 263344 & 5.85367 & 0.3662 \\
\hline 98 & e & e & 263302 & 1.51455 & 0.6587 & $\mathrm{w}$ & 263301 & 3.4484 & 0.2505 \\
\hline 99 & $\mathrm{e}$ & $\mathrm{e}$ & 263290 & 0.781306 & 0.3825 & $\mathrm{w}$ & 263290 & 1.40453 & 0.2801 \\
\hline 100 & $\mathrm{e}$ & $\mathrm{e}$ & 263280 & 3.0155 & 0.6984 & $\mathrm{w}$ & 263279 & 5.38804 & 0.2133 \\
\hline 101 & $\mathrm{e}$ & e & 263310 & 0.303126 & 0.5281 & $\mathrm{w}$ & 263310 & 1.35291 & 0.3124 \\
\hline 102 & e & e & 263309 & 0.750599 & 0.5432 & $\mathrm{w}$ & 263308 & 1.92519 & 0.3019 \\
\hline 103 & e & e & 263297 & 1.41181 & 0.6171 & $\mathrm{w}$ & 263297 & 3.09412 & 0.2661 \\
\hline 104 & e & $\mathrm{e}$ & 263273 & 5.0622 & 0.7285 & $\mathrm{w}$ & 263271 & 7.71463 & 0.1934 \\
\hline 105 & $\mathrm{e}$ & $\mathrm{e}$ & 263311 & 0.437637 & 0.603 & $\mathrm{w}$ & 263311 & 1.90785 & 0.2891 \\
\hline 106 & e & $\mathrm{e}$ & 263319 & 1.84284 & 0.5494 & w & 263318 & 2.94837 & 0.3161 \\
\hline 107 & $\mathrm{e}$ & $*_{\mathrm{r}}$ & 263296 & 1.68545 & 0.44 & $\mathrm{w}$ & 263295 & 3.39992 & 0.1867 \\
\hline 108 & e & $*_{\mathrm{r}}$ & 263286 & 0.875928 & 0.3475 & w & 263286 & 1.86788 & 0.2116 \\
\hline 109 & e & $\mathrm{e}$ & 263265 & 3.51752 & 0.3167 & $\mathrm{r}$ & 263265 & 3.78759 & 0.2767 \\
\hline 110 & e & $\mathrm{e}$ & 263313 & 2.36718 & 0.3414 & w & 263313 & 2.49253 & 0.3207 \\
\hline 111 & e & $\mathrm{e}$ & 263334 & 2.9092 & 0.639 & $\mathrm{w}$ & 263333 & 4.44596 & 0.2964 \\
\hline 112 & e & $\mathrm{e}$ & 263323 & 1.60184 & 0.6474 & $\mathrm{w}$ & 263322 & 3.27302 & 0.2807 \\
\hline 113 & $\mathrm{e}$ & $\mathrm{e}$ & 263313 & 3.03356 & 0.769 & $\mathrm{w}$ & 263312 & 5.73921 & 0.1988 \\
\hline 114 & $\mathrm{e}$ & $\mathrm{e}$ & 263285 & 1.43349 & 0.6271 & $\mathrm{w}$ & 263284 & 3.31531 & 0.2447 \\
\hline 115 & $\mathrm{e}$ & $\mathrm{e}$ & 263314 & 3.68124 & 0.8099 & $\mathrm{w}$ & 263313 & 6.80732 & 0.1697 \\
\hline 116 & e & $\mathrm{e}$ & 263274 & 4.63719 & 0.7651 & w & 263272 & 7.5658 & 0.1769 \\
\hline 117 & $\mathrm{e}$ & $\mathrm{e}$ & 263321 & 2.25078 & 0.7364 & $\mathrm{w}$ & 263320 & 4.61735 & 0.2255 \\
\hline
\end{tabular}




\begin{tabular}{|c|c|c|c|c|c|c|c|c|c|}
\hline \multirow{2}{*}{ Row } & \multirow{2}{*}{$\begin{array}{l}\text { Actual } \\
\text { Group }\end{array}$} & \multirow{2}{*}{$\begin{array}{l}\text { Highest } \\
\text { Group }\end{array}$} & \multirow{2}{*}{$\begin{array}{l}\text { Highest } \\
\text { Value }\end{array}$} & \multirow{2}{*}{$\begin{array}{l}\text { Squared } \\
\text { Distance }\end{array}$} & \multirow{2}{*}{ Prob. } & \multirow{2}{*}{$\begin{array}{l}\text { 2nd Highest } \\
\text { Group }\end{array}$} & \multirow{2}{*}{$\begin{array}{l}\text { 2nd Highest } \\
\text { Value }\end{array}$} & \multirow{2}{*}{$\begin{array}{l}\text { Squared } \\
\text { Distance }\end{array}$} & \multirow{2}{*}{ Prob. } \\
\hline & & & & & & & & & \\
\hline 118 & $\mathrm{e}$ & $\mathrm{e}$ & 263327 & 2.08234 & 0.6515 & $\mathrm{w}$ & 263326 & 3.75474 & 0.2823 \\
\hline 119 & $\mathrm{e}$ & $\mathrm{e}$ & 263284 & 1.08144 & 0.6586 & w & 263283 & 3.16669 & 0.2322 \\
\hline 120 & $\mathrm{e}$ & $\mathrm{e}$ & 263295 & 1.4689 & 0.7596 & w & 263294 & 4.18787 & 0.1951 \\
\hline 121 & $\mathrm{e}$ & e & 263292 & 2.66088 & 0.5316 & w & 263291 & 3.9277 & 0.2822 \\
\hline 122 & $\mathrm{e}$ & e & 263295 & 1.4689 & 0.7596 & w & 263294 & 4.18787 & 0.1951 \\
\hline 123 & e & e & 263280 & 4.33962 & 0.6461 & w & 263279 & 6.37089 & 0.234 \\
\hline 124 & e & e & 263279 & 1.66312 & 0.5999 & w & 263279 & 3.47097 & 0.243 \\
\hline 125 & $\mathrm{e}$ & $\mathrm{e}$ & 263315 & 0.51406 & 0.6389 & w & 263314 & 2.18896 & 0.2765 \\
\hline 126 & $\mathrm{e}$ & $\mathrm{e}$ & 263272 & 2.88592 & 0.4742 & w & 263272 & 4.2058 & 0.2451 \\
\hline 127 & e & e & 263296 & 0.876421 & 0.6251 & w & 263295 & 2.62408 & 0.2609 \\
\hline 128 & e & e & 263310 & 0.643232 & 0.5546 & w & 263310 & 1.83727 & 0.3053 \\
\hline 129 & $\mathrm{e}$ & $\mathrm{e}$ & 263299 & 0.556122 & 0.6216 & w & 263298 & 2.2853 & 0.2618 \\
\hline 130 & e & $\mathrm{e}$ & 263285 & 1.58973 & 0.7231 & w & 263284 & 4.09542 & 0.2066 \\
\hline 131 & $\mathrm{e}$ & e & 263296 & 1.60058 & 0.3508 & w & 263296 & 2.06845 & 0.2777 \\
\hline 132 & e & e & 263241 & 20.3701 & 0.5256 & $\mathrm{r}$ & 263240 & 22.1704 & 0.2137 \\
\hline 133 & e & e & 263298 & 0.704482 & 0.7102 & $\mathrm{w}$ & 263297 & 3.00424 & 0.2249 \\
\hline 134 & e & e & 263293 & 0.756636 & 0.7127 & w & 263292 & 3.12052 & 0.2186 \\
\hline 135 & e & e & 263329 & 1.84379 & 0.4881 & w & 263329 & 2.47955 & 0.3552 \\
\hline 136 & e & e & 263335 & 2.74903 & 0.4855 & w & 263335 & 3.31449 & 0.366 \\
\hline 137 & $\mathrm{e}$ & $\mathrm{e}$ & 263315 & 0.687011 & 0.474 & $\mathrm{w}$ & 263315 & 1.39033 & 0.3335 \\
\hline 138 & $\mathrm{e}$ & $\mathrm{e}$ & 263282 & 2.298 & 0.6904 & w & 263281 & 4.59903 & 0.2185 \\
\hline 139 & $\mathrm{e}$ & $\mathrm{e}$ & 263286 & 0.983223 & 0.3653 & w & 263286 & 1.66441 & 0.2599 \\
\hline 140 & e & e & 263294 & 0.797287 & 0.5838 & w & 263293 & 2.33412 & 0.2707 \\
\hline 141 & e & $\mathrm{e}$ & 263301 & 0.237512 & 0.4303 & w & 263300 & 0.929764 & 0.3044 \\
\hline 142 & e & e & 263328 & 2.27045 & 0.6224 & w & 263328 & 3.73325 & 0.2995 \\
\hline 143 & $\mathrm{e}$ & $\mathrm{e}$ & 263290 & 1.59418 & 0.5547 & w & 263289 & 3.10364 & 0.2608 \\
\hline 144 & e & e & 263331 & 2.63401 & 0.6552 & w & 263330 & 4.30764 & 0.2838 \\
\hline 145 & e & e & 263309 & 0.575169 & 0.5166 & w & 263308 & 1.61167 & 0.3077 \\
\hline 146 & e & e & 263312 & 1.54306 & 0.7204 & $\mathrm{w}$ & 263311 & 3.83443 & 0.2291 \\
\hline 147 & e & ${ }^{*} \mathrm{~W}$ & 263308 & 2.05838 & 0.3004 & e & 263308 & 2.07262 & 0.2983 \\
\hline 148 & $\mathrm{e}$ & $*_{r}$ & 263289 & 2.50691 & 0.3842 & w & 263289 & 3.39692 & 0.2462 \\
\hline 149 & $\mathrm{e}$ & $\mathrm{e}$ & 263267 & 7.84914 & 0.5339 & w & 263266 & 9.46247 & 0.2383 \\
\hline 150 & $\mathrm{e}$ & e & 263286 & 1.6261 & 0.7416 & w & 263285 & 4.26988 & 0.1977 \\
\hline 151 & $\mathrm{e}$ & $*_{\mathrm{r}}$ & 263326 & 2.89343 & 0.4008 & w & 263326 & 3.44268 & 0.3046 \\
\hline 152 & e & $\mathrm{e}$ & 263291 & 0.5681 & 0.4781 & w & 263291 & 1.61176 & 0.2837 \\
\hline 153 & e & $\mathrm{e}$ & 263320 & 1.494 & 0.7022 & w & 263319 & 3.58439 & 0.2469 \\
\hline 154 & e & e & 263339 & 3.36943 & 0.4919 & w & 263339 & 3.93612 & 0.3705 \\
\hline 155 & e & e & 263280 & 1.18674 & 0.5697 & w & 263279 & 2.85034 & 0.248 \\
\hline 156 & e & $\mathrm{e}$ & 263317 & 2.90105 & 0.7857 & w & 263316 & 5.75218 & 0.1889 \\
\hline 157 & e & $*_{\mathrm{r}}$ & 263309 & 1.14256 & 0.3115 & w & 263309 & 1.15814 & 0.3091 \\
\hline 158 & e & $\mathrm{e}$ & 263297 & 1.00421 & 0.4134 & w & 263297 & 1.63606 & 0.3014 \\
\hline 159 & e & $* \mathrm{r}$ & 263320 & 2.00448 & 0.3552 & w & 263320 & 2.15024 & 0.3303 \\
\hline 160 & e & e & 263265 & 4.21504 & 0.4395 & $\mathrm{r}$ & 263264 & 5.46907 & 0.2348 \\
\hline 161 & $\mathrm{e}$ & $\mathrm{e}$ & 263314 & 1.49222 & 0.4482 & w & 263314 & 2.06361 & 0.3368 \\
\hline 162 & $\mathrm{e}$ & $\mathrm{e}$ & 263287 & 0.624206 & 0.5635 & w & 263286 & 2.15243 & 0.2624 \\
\hline 163 & e & $\mathrm{e}$ & 263290 & 1.52025 & 0.7625 & w & 263289 & 4.30334 & 0.1896 \\
\hline 164 & e & $\mathrm{e}$ & 263321 & 3.92416 & 0.8004 & w & 263320 & 6.9146 & 0.1795 \\
\hline 165 & e & e & 263321 & 2.25078 & 0.7364 & w & 263320 & 4.61735 & 0.2255 \\
\hline 166 & e & $\mathrm{e}$ & 263289 & 2.07229 & 0.7631 & w & 263288 & 4.86155 & 0.1892 \\
\hline 167 & $\mathrm{e}$ & $\mathrm{e}$ & 263301 & 1.96695 & 0.4293 & w & 263301 & 2.7125 & 0.2957 \\
\hline 168 & e & $\mathrm{e}$ & 263302 & 2.19225 & 0.8052 & w & 263300 & 5.32082 & 0.1685 \\
\hline 169 & e & $*_{\mathrm{r}}$ & 263303 & 0.739077 & 0.3538 & w & 263303 & 1.28623 & 0.2691 \\
\hline 170 & e & $\mathrm{e}$ & 263289 & 0.626525 & 0.4573 & w & 263289 & 1.65663 & 0.2732 \\
\hline 171 & e & $\mathrm{e}$ & 263317 & 0.620179 & 0.5765 & w & 263316 & 1.88202 & 0.3068 \\
\hline 172 & $\mathrm{e}$ & e & 263292 & 0.629164 & 0.6494 & w & 263291 & 2.57878 & 0.245 \\
\hline 173 & $\mathrm{e}$ & $\mathrm{e}$ & 263309 & 0.910641 & 0.7099 & w & 263308 & 3.13544 & 0.2334 \\
\hline 174 & $\mathrm{e}$ & $\mathrm{e}$ & 263297 & 0.674076 & 0.67 & w & 263296 & 2.69766 & 0.2436 \\
\hline 175 & $\mathrm{e}$ & e & 263309 & 0.575169 & 0.5166 & w & 263308 & 1.61167 & 0.3077 \\
\hline 176 & e & $*_{\mathrm{w}}$ & 263323 & 2.00753 & 0.355 & e & 263323 & 2.20798 & 0.3211 \\
\hline 177 & e & $*_{\mathrm{r}}$ & 263288 & 1.98753 & 0.3037 & e & 263288 & 2.70256 & 0.2124 \\
\hline 178 & e & $\mathrm{e}$ & 263304 & 0.303498 & 0.6662 & w & 263303 & 2.2509 & 0.2516 \\
\hline 179 & $\mathrm{e}$ & $*_{\mathrm{r}}$ & 263308 & 0.915298 & 0.3568 & w & 263308 & 1.32576 & 0.2906 \\
\hline 180 & $\mathrm{e}$ & $\mathrm{e}$ & 263330 & 2.04731 & 0.6143 & $\mathrm{w}$ & 263329 & 3.44502 & 0.3054 \\
\hline
\end{tabular}




\begin{tabular}{|c|c|c|c|c|c|c|c|c|c|}
\hline \multirow{2}{*}{ Row } & \multirow{2}{*}{$\begin{array}{l}\text { Actual } \\
\text { Group }\end{array}$} & \multirow{2}{*}{$\begin{array}{l}\text { Highest } \\
\text { Group }\end{array}$} & \multirow{2}{*}{$\begin{array}{l}\text { Highest } \\
\text { Value }\end{array}$} & \multirow{2}{*}{$\frac{\text { Squared }}{\text { Distance }}$} & \multirow{2}{*}{ Prob. } & \multirow{2}{*}{$\begin{array}{l}\text { 2nd Highest } \\
\text { Group }\end{array}$} & \multirow{2}{*}{$\begin{array}{l}\text { 2nd Highest } \\
\text { Value }\end{array}$} & \multirow{2}{*}{$\begin{array}{l}\text { Squared } \\
\text { Distance }\end{array}$} & \multirow{2}{*}{ Prob. } \\
\hline & & & & & & & & & \\
\hline 181 & e & ${ }^{*} \mathrm{~W}$ & 263322 & 2.14979 & 0.3496 & $\mathrm{r}$ & 263322 & 2.37287 & 0.3127 \\
\hline 182 & e & e & 263297 & 0.553969 & 0.6979 & $\mathrm{w}$ & 263295 & 2.78099 & 0.2292 \\
\hline . & . & . & . & . & . & . & . & . & . \\
\hline . & . & . & . & . & . & . & . & . & . \\
\hline . & . & . & . & . & . & . & . & . & . \\
\hline 913 & w & w & 262297 & 6.8555 & 0.4844 & $\mathrm{r}$ & 262297 & 7.2855 & 0.3907 \\
\hline 914 & w & $* \mathrm{e}$ & 263300 & 0.558083 & 0.3707 & $\mathrm{w}$ & 263299 & 0.974156 & 0.3011 \\
\hline 915 & w & $*_{\mathrm{e}}$ & 263307 & 0.538307 & 0.3961 & $\mathrm{w}$ & 263307 & 0.95683 & 0.3213 \\
\hline 916 & w & w & 262251 & 1.60299 & 0.521 & $\mathrm{e}$ & 262251 & 2.41744 & 0.3467 \\
\hline 917 & w & $* \mathrm{e}$ & 263295 & 1.12119 & 0.5861 & $\mathrm{w}$ & 263294 & 2.70489 & 0.2655 \\
\hline 918 & w & $*_{\mathrm{e}}$ & 263306 & 0.352091 & 0.4347 & $\mathrm{w}$ & 263306 & 0.980218 & 0.3175 \\
\hline 919 & w & $*_{\mathrm{r}}$ & 263292 & 0.708351 & 0.3588 & $\mathrm{~h}$ & 263291 & 1.60071 & 0.2297 \\
\hline 920 & $\mathrm{w}$ & w & 262259 & 1.96504 & 0.4916 & $\mathrm{r}$ & 262258 & 2.87881 & 0.3113 \\
\hline 921 & w & $* h$ & 263269 & 1.95497 & 0.3553 & $\mathrm{r}$ & 263269 & 2.34554 & 0.2922 \\
\hline 922 & $\mathrm{w}$ & $* g$ & 261153 & 4.39359 & 0.8402 & $\mathrm{r}$ & 261151 & 8.78819 & 0.0933 \\
\hline 923 & $\mathrm{w}$ & $\mathrm{w}$ & 262249 & 3.33382 & 0.4842 & $\mathrm{r}$ & 262248 & 4.30831 & 0.2975 \\
\hline 924 & $\mathrm{w}$ & w & 262205 & 9.53868 & 0.4045 & e & 262204 & 10.1388 & 0.2996 \\
\hline 925 & w & w & 261188 & 4.05228 & 0.4631 & $\mathrm{~g}$ & 261187 & 5.05645 & 0.2803 \\
\hline 926 & $\mathrm{w}$ & $* \mathrm{r}$ & 263291 & 7.06487 & 0.4345 & $\mathrm{~h}$ & 263290 & 7.83502 & 0.2957 \\
\hline 927 & $\mathrm{w}$ & $\mathrm{w}$ & 261189 & 5.66834 & 0.6711 & $\mathrm{r}$ & 261188 & 9.01728 & 0.1258 \\
\hline 928 & $\mathrm{w}$ & $*_{\mathrm{e}}$ & 263297 & 2.55968 & 0.3473 & w & 263297 & 2.85 & 0.3004 \\
\hline 929 & $\mathrm{w}$ & w & 262218 & 4.30627 & 0.4042 & $\mathrm{r}$ & 262217 & 5.1983 & 0.2588 \\
\hline 930 & w & *g & 260116 & 14.9224 & 0.4453 & $\mathrm{w}$ & 260116 & 15.0015 & 0.4281 \\
\hline 931 & $\mathrm{w}$ & $* r$ & 263318 & 2.50473 & 0.4484 & $\mathrm{w}$ & 263318 & 3.44026 & 0.2809 \\
\hline 932 & $\mathrm{w}$ & w & 262207 & 6.26982 & 0.2986 & $\mathrm{r}$ & 262207 & 6.2701 & 0.2985 \\
\hline 933 & w & w & 261169 & 7.16851 & 0.5817 & $\mathrm{~g}$ & 261168 & 9.81915 & 0.1546 \\
\hline 934 & w & w & 261190 & 4.86953 & 0.5106 & $\mathrm{~g}$ & 261189 & 6.35082 & 0.2435 \\
\hline 935 & w & w & 262267 & 1.34679 & 0.5714 & $\mathrm{e}$ & 262266 & 2.91804 & 0.2605 \\
\hline 936 & $\mathrm{w}$ & $*_{\mathrm{r}}$ & 262252 & 1.20763 & 0.3608 & $\mathrm{~g}$ & 262252 & 1.33978 & 0.3377 \\
\hline 937 & w & w & 262232 & 3.67251 & 0.3179 & $\mathrm{r}$ & 262232 & 3.98965 & 0.2713 \\
\hline 938 & $\mathrm{w}$ & $*_{\mathrm{r}}$ & 263319 & 1.75623 & 0.3467 & $\mathrm{w}$ & 263319 & 1.87595 & 0.3265 \\
\hline 939 & $\mathrm{w}$ & $*_{\mathrm{r}}$ & 263349 & 8.00885 & 0.5114 & $\mathrm{w}$ & 263348 & 9.01594 & 0.3091 \\
\hline 940 & $\mathrm{w}$ & $\mathrm{w}$ & 262262 & 1.93686 & 0.4361 & $\mathrm{r}$ & 262262 & 2.54264 & 0.3222 \\
\hline 941 & $\mathrm{w}$ & $* \mathrm{r}$ & 263275 & 3.01569 & 0.347 & $\mathrm{e}$ & 263275 & 3.68749 & 0.248 \\
\hline 942 & w & $* \mathrm{e}$ & 263317 & 0.889507 & 0.4374 & $\mathrm{w}$ & 263317 & 1.38322 & 0.3417 \\
\hline 943 & w & $*_{\mathrm{e}}$ & 263318 & 0.678704 & 0.6223 & w & 263317 & 2.217 & 0.2884 \\
\hline 944 & $\mathrm{w}$ & $* h$ & 263283 & 0.805881 & 0.4234 & $\mathrm{r}$ & 263283 & 1.67768 & 0.2738 \\
\hline 945 & $\mathrm{w}$ & $\mathrm{w}$ & 261206 & 4.29759 & 0.4637 & $\mathrm{r}$ & 261206 & 5.49854 & 0.2544 \\
\hline 946 & $\mathrm{w}$ & $*_{\mathrm{e}}$ & 263270 & 2.39781 & 0.4854 & $\mathrm{w}$ & 263269 & 3.84839 & 0.235 \\
\hline 947 & $\mathrm{w}$ & $*_{\mathrm{e}}$ & 263308 & 0.282265 & 0.4829 & w & 263308 & 1.12122 & 0.3174 \\
\hline 948 & w & $\mathrm{w}$ & 262243 & 1.18312 & 0.4351 & $\mathrm{r}$ & 262242 & 2.15117 & 0.2681 \\
\hline 949 & w & $*_{\mathrm{e}}$ & 263301 & 1.01974 & 0.4638 & w & 263301 & 1.90927 & 0.2973 \\
\hline 950 & $\mathrm{w}$ & $*_{\mathrm{e}}$ & 263297 & 0.385144 & 0.6306 & $\mathrm{w}$ & 263296 & 2.18556 & 0.2563 \\
\hline 951 & $\mathrm{w}$ & $*_{\mathrm{e}}$ & 263287 & 1.29586 & 0.5649 & $\mathrm{w}$ & 263287 & 2.87684 & 0.2563 \\
\hline 952 & $\mathrm{w}$ & $\mathrm{w}$ & 261219 & 5.00107 & 0.6165 & $\mathrm{r}$ & 261218 & 7.08509 & 0.2175 \\
\hline 953 & $\mathrm{w}$ & $*_{\mathrm{e}}$ & 263292 & 0.609023 & 0.5655 & w & 263291 & 2.07312 & 0.272 \\
\hline 954 & w & w & 261202 & 5.30642 & 0.6736 & $\mathrm{r}$ & 261201 & 8.36247 & 0.1461 \\
\hline 955 & w & w & 262266 & 1.77418 & 0.5669 & $\mathrm{e}$ & 262265 & 3.28624 & 0.2662 \\
\hline 956 & $\mathrm{w}$ & $*_{\mathrm{r}}$ & 263320 & 2.49712 & 0.3555 & $\mathrm{w}$ & 263320 & 2.77949 & 0.3087 \\
\hline 957 & $\mathrm{w}$ & $*_{\mathrm{e}}$ & 263316 & 1.64346 & 0.3576 & w & 263316 & 1.77593 & 0.3347 \\
\hline 958 & $\mathrm{w}$ & w & 262258 & 2.77047 & 0.4559 & $\mathrm{r}$ & 262257 & 3.28935 & 0.3517 \\
\hline 959 & $\mathrm{w}$ & $\mathrm{w}$ & 262243 & 0.836017 & 0.4542 & $\mathrm{r}$ & 262243 & 1.71723 & 0.2923 \\
\hline 960 & w & $*_{\mathrm{e}}$ & 263318 & 2.32255 & 0.7162 & $\mathrm{w}$ & 263317 & 4.54363 & 0.2359 \\
\hline 961 & w & $*_{\mathrm{r}}$ & 263312 & 1.91358 & 0.3948 & w & 263312 & 3.09637 & 0.2185 \\
\hline 962 & $\mathrm{w}$ & $*_{\mathrm{r}}$ & 262251 & 0.778578 & 0.3647 & $\mathrm{w}$ & 262251 & 1.08196 & 0.3134 \\
\hline 963 & $\mathrm{w}$ & w & 263352 & 6.76886 & 0.4265 & $\mathrm{e}$ & 263352 & 7.51776 & 0.2933 \\
\hline 964 & $\mathrm{w}$ & w & 261182 & 4.89619 & 0.5059 & $\mathrm{~g}$ & 261181 & 6.32623 & 0.2475 \\
\hline 965 & $\mathrm{w}$ & $\mathrm{w}$ & 262257 & 1.3866 & 0.5487 & e & 262256 & 3.0925 & 0.2338 \\
\hline 966 & w & $*_{\mathrm{r}}$ & 263299 & 1.26018 & 0.3104 & $\mathrm{e}$ & 263298 & 1.49431 & 0.2761 \\
\hline 967 & $\mathrm{w}$ & $*_{\mathrm{e}}$ & 263294 & 1.61637 & 0.5492 & $\mathrm{w}$ & 263294 & 2.94976 & 0.282 \\
\hline 968 & $\mathrm{w}$ & $*_{\mathrm{e}}$ & 263300 & 2.19279 & 0.8108 & w & 263298 & 5.39287 & 0.1637 \\
\hline 969 & $\mathrm{w}$ & $*_{\mathrm{r}}$ & 263337 & 4.98619 & 0.4929 & w & 263337 & 6.24057 & 0.2632 \\
\hline 970 & $\mathrm{w}$ & $\mathrm{w}$ & 263338 & 4.68794 & 0.3891 & $\mathrm{r}$ & 263338 & 5.14101 & 0.3102 \\
\hline
\end{tabular}




\begin{tabular}{|c|c|c|c|c|c|c|c|c|c|}
\hline \multirow{2}{*}{ Row } & \multirow{2}{*}{$\begin{array}{l}\text { Actual } \\
\text { Group } \\
\end{array}$} & \multirow{2}{*}{$\begin{array}{l}\text { Highest } \\
\text { Group } \\
\end{array}$} & \multirow{2}{*}{$\begin{array}{l}\text { Highest } \\
\text { Value } \\
\end{array}$} & \multirow{2}{*}{$\begin{array}{l}\text { Squared } \\
\text { Distance } \\
\end{array}$} & \multirow{2}{*}{ Prob. } & \multirow{2}{*}{$\begin{array}{l}\text { 2nd Highest } \\
\text { Group }\end{array}$} & \multirow{2}{*}{\begin{tabular}{|l|} 
2nd Highest \\
Value \\
\end{tabular}} & \multirow{2}{*}{$\begin{array}{l}\text { Squared } \\
\text { Distance } \\
\end{array}$} & \multirow{2}{*}{ Prob. } \\
\hline & & & & & & & & & \\
\hline 971 & $\mathrm{w}$ & $*_{\mathrm{e}}$ & 263288 & 0.583037 & 0.499 & $\mathrm{w}$ & 263287 & 1.82275 & 0.2685 \\
\hline 972 & w & $*_{\mathrm{e}}$ & 263339 & 3.49047 & 0.5158 & w & 263339 & 4.19525 & 0.3626 \\
\hline 973 & $\mathrm{w}$ & w & 262258 & 1.5635 & 0.3871 & $\mathrm{r}$ & 262257 & 1.80911 & 0.3423 \\
\hline 974 & w & $*_{\mathrm{r}}$ & 263273 & 2.25524 & 0.2879 & $\mathrm{~h}$ & 263273 & 2.39444 & 0.2685 \\
\hline 975 & w & w & 261210 & 4.89524 & 0.596 & $\mathrm{r}$ & 261209 & 6.81651 & 0.2281 \\
\hline 976 & $\mathrm{w}$ & $* \mathrm{~h}$ & 263297 & 2.29402 & 0.3938 & $\mathrm{r}$ & 263297 & 2.87603 & 0.2943 \\
\hline 977 & w & $* \mathrm{e}$ & 263314 & 1.15481 & 0.3625 & w & 263314 & 1.2996 & 0.3372 \\
\hline 978 & w & w & 262228 & 2.07541 & 0.3517 & $\mathrm{r}$ & 262228 & 2.58998 & 0.2719 \\
\hline 979 & w & $*_{\mathrm{r}}$ & 263328 & 3.54526 & 0.3863 & w & 263328 & 3.78649 & 0.3424 \\
\hline 980 & w & $*_{\mathrm{e}}$ & 263310 & 0.303126 & 0.5281 & w & 263310 & 1.35291 & 0.3124 \\
\hline 981 & w & $*_{\mathrm{r}}$ & 263306 & 1.34984 & 0.315 & w & 263306 & 1.51078 & 0.2907 \\
\hline 982 & w & $*_{\mathrm{r}}$ & 263335 & 6.32257 & 0.5516 & w & 263334 & 8.00663 & 0.2377 \\
\hline 983 & w & $*_{\mathrm{g}}$ & 262224 & 1.15157 & 0.3611 & $\mathrm{r}$ & 262224 & 1.56673 & 0.2934 \\
\hline 984 & w & $*$ & 263310 & 1.41283 & 0.4387 & w & 263310 & 1.983 & 0.3299 \\
\hline 985 & w & $\mathrm{w}$ & 262242 & 2.4498 & 0.3368 & $\mathrm{r}$ & 262242 & 2.66287 & 0.3028 \\
\hline 986 & w & $* \mathrm{~g}$ & 261184 & 4.78087 & 0.5328 & w & 261183 & 6.24223 & 0.2566 \\
\hline 987 & w & w & 262239 & 2.03947 & 0.495 & $\mathrm{e}$ & 262239 & 2.71362 & 0.3533 \\
\hline 988 & w & $*_{\mathrm{r}}$ & 262245 & 2.55275 & 0.4008 & g & 262245 & 2.86909 & 0.3422 \\
\hline 989 & w & $*_{\mathrm{e}}$ & 263257 & 7.09848 & 0.5506 & $\mathrm{w}$ & 263256 & 8.97815 & 0.2151 \\
\hline 990 & w & $\mathrm{w}$ & 262266 & 1.07911 & 0.5679 & e & 262265 & 2.9327 & 0.2248 \\
\hline 991 & w & $*_{\mathrm{e}}$ & 263285 & 1.61155 & 0.7033 & $\mathrm{w}$ & 263284 & 3.97915 & 0.2153 \\
\hline 992 & w & $*_{\mathrm{e}}$ & 263299 & 3.50479 & 0.3405 & $\mathrm{r}$ & 263298 & 3.71411 & 0.3067 \\
\hline 993 & w & w & 262249 & 0.284409 & 0.4861 & $\mathrm{r}$ & 262248 & 1.54317 & 0.259 \\
\hline 994 & w & $*_{\mathrm{e}}$ & 263275 & 4.11977 & 0.7209 & w & 263273 & 6.70068 & 0.1984 \\
\hline 995 & $\mathrm{w}$ & $*_{\mathrm{e}}$ & 263316 & 1.70664 & 0.6374 & $\mathrm{w}$ & 263315 & 3.3692 & 0.2776 \\
\hline 996 & w & $\mathrm{w}$ & 262275 & 2.33474 & 0.4541 & $\mathrm{r}$ & 262274 & 2.78425 & 0.3627 \\
\hline 997 & w & $*_{\mathrm{e}}$ & 263311 & 0.391118 & 0.6103 & w & 263310 & 1.92053 & 0.2841 \\
\hline 998 & w & w & 262261 & 4.10211 & 0.5076 & $\mathrm{e}$ & 262261 & 4.506 & 0.4148 \\
\hline 999 & w & w & 261222 & 5.40593 & 0.7207 & $\mathrm{r}$ & 261220 & 8.4337 & 0.1586 \\
\hline
\end{tabular}

* = incorrectly classified.

\section{References}

[1] Büyüköztürk, S. and Cokluk-Bökeoğlu, O. (2008) "Discriminant Function Analysis: Concept and Application", Eurasian Journal of Educational Research, 33, PP. 73-74.

[2] Alexakos, C. E. (1966) "Predictive Efficiency of two Multivariate Statistical Techniques in Comparison with Clinical Predictions", Journal of Educational Psychology, 57, PP. 297-306.

[3] Chastian, K. (1969) "Prediction of Success in Audio-lingual and Cognitive Classes", Lan-guage Learning, 19, PP. 27-39.

[4] Stahmann, R. F. (1969) "Predicting Graduation Major Field from Freshman Entrance Data", Journal of Counseling Psychology, Vol. 16, PP. 109-113.

[5] Anderson, G. J., Walberg, H. J., and Welch, W. W. (1969) "Curriculum Effects on the Social Climate of Learning: A new Representation of Discriminant Functions", American Educational Research Journal, No. 6, PP. 315-328.

[6] Saupe, J. L. (1965) "Factorial-design Multiple Discriminant Analysis: A description and An illustration", American Educational Research Journal, Vol. 2, PP. 175-184.

[7] Tatsuoka, M. M., and Tiedeman, D. V. (1954) "Discriminant Analysis. Review of Educational Research", No. 24, PP. 402-420.

[8] Fisher, R. A. (1936) "The Use of Multiple Measurements in Taxonomic Problems", Annals of Eugenics, 7.

[9] Fisher, R. A. (1938) "The Statistical Utilization of Multiple Measurements", Annals of Eugenics, Vol. 8, PP. 376-386.

[10] Solovyev, V. and Salamov, A. (1997) "The Gene-Finder Computer Tools for Analysis of Human and Model Organisms Genome Sequences", Department of Cell Biology, Baylor College of Medicine, One Baylor Plaza, Houston, TX, American Association for Artificial Intelligence (www.aaai.org), PP. 294- 302.

[11] Ghosh, D. (1993). "Status of the Transcription Factors Database (TFD)". Nucl. Acids Res., Vol. 21, PP. 3117-3118.

[12] Wingender, E. (1994) "Recognition of Regulatory Regions Genomic Sequences”, J. Biotechnol. 35, PP. 273-280.

[13] Zhang, M. Q. (2000) "Discriminant Analysis and its Application in DNA Sequence Motif Recognition", Henry Stewart Publications 1467-5463, Briefings in Bionformatics, Vol. 1, No. 4.

[14] Dudoit, S., Fridlyand, J. and Speed, T. P. (2000) "Comparison of Discrimination Methods for the Classification of Tumors Using Gene Expression Data", Department of Statistics, University of California, Berkeley, Berkeley, CA 94720-3860, sandrine@stat.berkeley.edu, PP. 1-43.

[15] Kwon, S., Chu, Y. H., Yi, H. S. and Han, C. (2001) "DNA Microarray Data Analysis for Cancer Classification Based on Stepwise Discriminant Analysis and Bayesian Decision Theory", Genome Informatics 12, PP. 252-254.

[16] Liu, Z. H., Jiao, D. and Sun, X. (2005) "Classifying Genomic Sequences by Sequence Feature Analysis", State Key Laboratory of Bioelectronics, Southeast University, Nanjing 210096, China, Geno. Prot. Bioinfo., Vol. 3, No. 4, PP. 201-205. 
[17] Guo, Y., Hastie, T. and Tibshirani, R. (2005) "Regularized Discriminant Analysis and Its Application in Microarrays", Printed in Great Britain, Biostatistics, Vol. 1, No. 1, PP. 1-18.

[18] Jombart, T., Devillard, S. and Balloux, F. (2010) "Discriminant Analysis of Principal Components: A new Method for the Analysis of Genetically Structured Populations", Jombart et al. BMC Genetics, 11:94, http://www.biomedcentral.com/1471-2156/11/94, PP. 1-15.

[19] Jin, J. and An, J. (2011) "Robust Discriminant Analysis and its Application to Identify Protein Coding Regions of Rice Genes", Contents lists available at Science Direct, Mathematical Biosciences, journal homepage: www.elsevier.com/locate/mbs

[20] Libbrecht, M. W. and Noble, W. S. (2015) "Machine Learning Applications in Genetics and Genomics", Nature Reviews | Genetics, Vol. 16, PP. 321-332.

[21] Corvelo, A., Clarke, W. E., Robine, N. and Zody, M. C. (2018) "TaxMaps: Comprehensive and Highly Accurate Taxonomic Classification of Short-read Data in Reasonable Time", New York Genome Center, New York 10013, USA, Published by Cold Spring Harbor Laboratory Press; ISSN 1088-9051/18; www.genome.org, Genome Research, Vol. 28, PP. 751-758.

[22] Polovinkina, A., Krylova, I., Druzhkova, P., Ivanchenkoa, M., Meyerova, I., Zaikina, A., and Zolotykha, N. (2016) "Solving Problems of Clustering and Classification of Cancer Diseases Based on DNA Methylation", Data Pattern Recognition and Image Analysis, Vol. 26, No. 1, PP. 176-180.

[23] Waterman, M. and Vingron, M. (1994) "Sequence Comparison Significance and Poisson Approximation", Stat. Sci., Vol. 9, PP. 367-381.

[24] McLachlan, A. and Stewart, M. (1976) "The 14-fold Periodicity in Alpha-Tropomyosin and the Interaction with Actin “, J. Mol. Biol., Vol. 103, PP. 271-298.

[25] Eisenberg, D., Weiss, R. M., Terwillger, T. C., (1994) "The Hydrophobic Moment Detects Periodicity in Protein Hydrophobicity". Proc. Natl. Acad. Sci., Vol. 81, PP. 140-144.

[26] Stoffer, D. (2012) "Frequency Domain Techniques in the Analysis of DNA Sequences", Handbook of Statistics Volume 30, PP. 261-295.

[27] Tavar'e, S., Giddings, B. (1989) "Some Statistical Aspects of the Primary Structure of Nucleotide Sequences", In Waterman M. S. (Ed), Mathematical Methods for DNA Sequences. CRC Press, Boca Raton, Florida, PP. 117-131.

[28] Viari, A., Soldano, H. and Ollivier, E. (1990) "A Scaleindependent Signal Processing Method for Sequence Analysis. Comput. Appl. Biosci., Vol. 6, PP. 71-80.

[29] Marhon, S. and Kremer, S. (2011) "Gene Prediction Based on DNA Spectral Analysis: A literature Review", J Comput Biol., Apr, Vol. 18, No. 4, 639-76.

[30] Bajic, V., Bajic, I. and Hide, W. (2000) "A new Method of
Spectral Analysis of DNA/RNA and Protein sequences" Centre for Engineering Research.

[31] Han, Y., Han, L., Yao, Y., Li, Y. and Liu, X. (2018) "Key Factors in FTIR Spectroscopic Analysis of DNA: The Sampling Technique, Pretreatment Temperature and Sample Concentration", Analytical Methods, Issue Vol. 21, No. 10, PP. 2436-2443.

[32] Ruiz, G., Israel, Godínez, I., Ramos, S., Ruiz, S., Pérez, H. and Morales, J. (2018) "Genomic Signal Processing for DNA Sequence Clustering” PeerJ v. 6; DOI 10.7717/peerj.4264.

[33] Hoang, T., Yin, C., Zheng, H. Yu, C., Lucy He, R. and Yau, S (2015) "A new Method to Cluster DNA Sequences Using Fourier Power Spectrum”, J Theor Biol. 7; 372:135-45.

[34] Mabrouk, M. (2017) “Advanced Genomic Signal Processing Methods in DNA Mapping Schemes for Gene Prediction Using Digital Filters", American Journal of Signal Processing, Vol. 7, No. 1, PP. 12-24.

[35] Roy, M. and Barman, S. (2011) "Spectral Analysis of Coding and Non-coding Regions of a DNA Sequence by Parametric and Nonparametric Methods: A comparative Approach", Annals of Faculty Engineering Hunedoara- International Journal Of Engineering; Tome IX; Faccicule 3; PP. 57-62.

[36] Galleani, L. and Garello, R. (2006) "Spectral Analysis of DNA Sequences by Entropy Minimization", 14th European Signal Processing Conference (EUSIPCO 2006), Florence, Italy, September, PP. 4-8.

[37] Stoffer, D., Tyler, D. and McDougall, A. (1993) "Spectral Analysis for Categorical Time Series: Scaling and the Spectral Envelope"; Biometrika, Vol. 80, PP. 611-622.

[38] Stankovičová, I. and Vojtková, M. (2007) "Viacrozmerné Statistické Metódy s Aplikáciami”, Bratislava, Iura Edition.

[39] Kočišová, K. and Mišanková, M. (2013) "Discriminant Analysis as A tool for Forecasting Company's Financial Health", Contemporary Issues in Business, Management and Education, University of Žilina, Faculty of Operation and Economics of Transport and Communications, Department of Economics, Procedia - Social and Behavioral Sciences 110, PP. 1148-1157.

[40] Meloun, M., Militký, J., and Hill, M. (2005) "Počítačová Analýza Vícerozměrných Dát v Príkladech”, Praha: Academia.

[41] Muhameed, A. S. and Saleh, A. M. (2014) "Classification of Some Iraqi Soils Using Discriminant Analysis", Dept. of Soil Sci. and Water Res. Agric. College - Univ. of Baghdad, IOSR Journal of Agriculture and Ve terinary Science (IOSR-JAVS), e-ISSN: 2319-2380, p-ISSN: 2319-2372., Vol. 7, Issue 1 Ver.

[42] Ayinla, A. S. and Adekunle, B. K. (2015) "An Overview and Application of Discriminant Analysis in Data Analysis", IOSR Journal of Mathematics (IOSR-JM), e-ISSN: 2278-5728, p-ISSN: 2319-765X, Volume 11, Issue 1 Ver. V, PP. 12-15.

[43] Härdle, W. K. and Simar, L. (2012) "Applied Multivariate Statistical Analysis", Sixth Edition. Copyrighted Material. 